\title{
Contribución al conocimiento de la anatomía macroscópica y microscópica de la tortuga sabanera Podocnemis vogli
}

\section{Contribution to the knowledge of the macroscopic and microscopic anatomy of turtle Podocnemis vogli}

\author{
Hernández Henao Javier ${ }^{1}$; Gonzales Gómez Mario Alfonso² y \\ Rodríguez Pulido José Ariel ${ }^{3}$ \\ ${ }^{1} \mathrm{MVZ}$. Unillanos QEPD; ${ }^{2} \mathrm{MV}$. MSc Docente Unillanos y \\ ${ }^{3}$ Biologo MSc Docente Unillanos \\ jose.rodriguez.pulido@unillanos.edu.co
}

Recibido 15 de Enero 2014, Aceptado 18 de Abril 2014

\section{RESUMEN}

Se describió la anatomía macroscópica y microscópica de los sistemas digestivo, respiratorio y urogenital de diez ejemplares de tortuga sabanera Podocnemis vogli (Pelomedusidae), cinco machos y cinco hembras, también se establecieron relaciones morfométricas de los órganos, la longitud recta de caparazón (LCR), ancho del mismo y peso del animal, estos ejemplares clínicamente sanos, procedentes del zoológico Bioparque los Ocarros de la ciudad de Villavicencio, fueron sometidos a una cuarentena por veinte días en un estanque con zona seca, ubicado en la granja de la Universidad de los Llanos, durante dicho periodo, los animales fueron alimentados con una dieta a base de concentrado que cubría el $70 \%$ del requerimiento energético diario (RED), fruta: banano y mango ( $20 \%$ RED) y Bore (10\% RED). El sacrificio de los animales se realizó utilizando Pentobarbital Sódico $31,4 \mathrm{mg} / \mathrm{kg}$. En las morfometrías se evaluó la Longitud Recta de Caparazón (LCR), la Longitud del Plastrón (LP), la Longitud de la Sutura Media Ventral (SMV), el Ancho del Caparazón (AC) y el Peso (W). La disección se llevó a cabo extrayendo el plastrón y separando el paquete visceral del caparazón y el estudio histológico de las muestras, se realizó con formalina bufferada al $10 \%$, en una proporción 1:10, con tinción de eosina-hematoxilina tradicional. En todos los procesos se realizaron registros fotográficos bajo condiciones controladas. Los 
resultados mostraron similitudes con los estudios hechos para reptiles, y las diferencias no son marcadas ya que conciernen principalmente en ubicación, forma y tamaño, lo cual se relaciona con las características biológicas específicas de la especie. Se hallaron modificaciones histológicas en comparación con los reptiles que marcan diferencias respecto a los epitelios y las túnicas estructurales del tubo digestivo, esta variabilidad se debe al tipo de alimentación y el comportamiento del bolo alimenticio en ese tracto.

Palabras clave: Reptiles, Podcnemis vogli, morfología, histología.

\begin{abstract}
The macroscopic and microscopic anatomy of the digestive, respiratory, and urogenital systems of ten specimens of turtle Podocnemis vogli (Pelomedusidae), five males and five females, were described morphometric relationships of organs were also established, the straight carapace length (LCR), height and weight of the same animal. These specimens were clinically healthy, the animals came from the Ocarros Biopark zoo in Villavicencio city, Meta, Colombia, they were subjected to quarantine for twenty days in a pond with dry area, located on the farm of the University of the Llanos. During this period, the animals were fed a diet of concentrate which covered $70 \%$ of the daily energy requirement (DER) Fruit: banana and mango 20\% DER, and bore 10\% DER. The sacrifice of animals was conducted using Pentobarbital sodium $31.4 \mathrm{mg} / \mathrm{kg}$. The morfometrías evaluated Straight Carapace Length (SCL), plastron length ( $P L)$, the length ventral suture media (LVS), the carapace width (CW) and the weight (W). The dissection was carried out by removing the plastron and visceral separation package shell and histology of the samples were realized with $10 \%$ buffered formalin, 1:10, and stained with hematoxylin-eosin traditional reading their cuts were performed with light microscopy 3-5 microns. Descriptive statistics (mean, standard deviation) and allometric relationships were used. In all processes photographic records were made under controlled conditions Results showed similarities with the studies made for reptiles, and the differences are not marked, since mainly concerning
\end{abstract}


location, shape and size, which is related to the specific biological characteristics of the species. Histological changes were found compared with reptiles that make differences in epithelia and structural robes gut, this variability will be due to the type of feeding and behavior of the bolus in this tract.

Keywords: Reptiles, Podcnemis vogli, anatomy, histology.

\section{INTRODUCCIÓN}

Desde la década del setenta en el siglo pasado, las investigaciones en fauna silvestre se han aumentado, siendo sus objetivos principales la conservación, su asociación con los ecosistemas y factores medioambientales, dentro de este desarrollo se ha profundizado en aspectos relacionados como: censos y dinámicas poblacionales y sus relaciones interespecíficas, sin embargo los reportes en biología enfocada a la morfofisiología son escasos, esta carencia está supeditada a la normatividad que rige la manipulación de estas especies, incrementada por el uso desequilibrado de dicho recurso y por el valor genético y biológico de las mismas (Avendaño, 2002).

La herpetofauna es una rama de investigación que valora tópicos básicos y ecológicos, siendo los primeros de gran interés dado la escasa información disponible. Colombia se caracteriza por su megadiversidad en fauna, siendo la región de la Orinoquia donde se encuentra Villavicencio, una de sus principales exponentes, así Colombia posee más del $14 \%$ de especies de tortugas del mundo, siendo la Podocnemis vogli endémica de los llanos orientales colombianos y occidentes de Venezuela. Los estudios realizados en esta especie son principalmente en su historia natural, hábitat, distribución y estado ecológico (Rueda y Rueda, 2003).

El desconocimiento de la anatomía macroscópica y microscópica de la fauna silvestre y en especial de las tortugas ha dificultado los planes de conservación y las alternativas productivas generadas a partir de este tipo de fauna. Lo cual impide comprender la fisiología y en su momento la patología macroscópica y 
microscópica. Los actuales planes de conservación y de alternativas productivas pecuarias han llevado a los biólogos, veterinarios y zootecnistas al manejo de la fauna silvestre (Ceballos, 2000).

Mundialmente se han generado programas de conservación y manejo in situ y ex situ, que tienen como objetivo prolongar la existencia de las especies de fauna silvestre más vulneradas, por ser un bien de la naturaleza que se debe proteger para conservar el equilibrio en los sistemas no intervenidos por el hombre. Esto aunado a que la sociedad debe buscar diferentes alternativas que eviten las producciones invasivas que atenten contra la biodiversidad. Los planes de zoocría de especies nativas son una oportunidad con potencial de producción, pero esta tarea es imposible de cumplir coherentemente si se desconocen las características básicas de las especies, puesto que no sólo por conocer su filogenia, estados poblacionales, distribución geográfica o historia natural se puede realizar un tratamiento médico, o un plan nutricional, o sencillamente un método de restricción (Avendaño, 2002).

Los estudios realizados en anatomía e histología de las tortugas son pocos: entre ellos se caracterizan los realizados en anatomía de tortugas marinas (Wyneken, 2001), anatomía e histología del sistema urogenital del morroco Geochelone carbonaria (Faria, 2003), algunas aproximaciones de Oros (2004) sobre anatomía e histología de tortugas del mediterráneo, además de otros estudios aislados en especies no Quelonias.

Los reportes en tortugas de Colombia son bastante escasos, encontrándose aproximaciones sobre la descripción macroscópica y microscópica de los sistemas digestivo y urogenital de la Terecay Podocnemis unifilis (Chacon, 2001). Viendo esta carencia de información desde el punto de vista de la biología básica, nace la motivación de la pesquisa sobre las características anatómicas de las especies de reptiles de la zona de la Orinoquía, por ser la tortuga sabanera Podocnemis vogli, endémica y para su potencial zootécnico como mascota se escogió esta especie para el presente estudio. 
De la escasa información acerca de las características de especies reptilianas, se plantea el desarrollo de este trabajo con el fin de contribuir con el conocimiento de la anatomía macroscópica y microscópica de los sistemas digestivo, respiratorio y urogenital, de esta especie, información que contribuirá a interpretar algunos procesos fisiológicos facilitando la comprensión de los hallazgos de necropsias o biopsias. Las estimaciones de los valores morfométricos y conocimiento de su anatomía son los pilares para la conservación de esta especie frente a la situación actual de la fauna en los bosques y ecosistemas de la Orinoquia. También, se direccionar actividades zootécnicas productivas a través de zoocriaderos, disminuyendo la presión sobre las poblaciones naturales.

\section{METODOLOGÍA}

Este trabajo se realizó en los Laboratorios de Biología e Histopatología de la Universidad de los Llanos, municipio de Villavicencio km 4 vía Puerto López, Meta Colombia, con las siguientes condiciones climatológicas medias anuales: temperatura promedio de $28^{\circ} \mathrm{C}$, precipitación anual de $4050 \mathrm{~mm}$, humedad relativa del $75 \%$ y una altura de $420 \mathrm{msnm}$.

Fueron utilizados un total de diez tortugas sabaneras (Podocnemis vogli) clínicamente sanas distribuidos así: cinco hembras con una longitud recta de caparazón (LRC) de $26.47 \mathrm{~cm}$ y cinco machos con una LRC de $19.11 \mathrm{~cm}$ en promedio, provenientes del zoológico "Bioparque Los Ocarros" ubicado en esta misma zona. Los animales fueron sometidos a cuarentena por veinte días en la granja de Unillanos sede Barcelona, donde fueron alimentados con dieta a base de concentrado que suministraba el $70 \%$ del requerimiento energético diario (RED), fruta: banano y mango que aportaban el $20 \%$ RED y bore que suplementaba el 10\% RED (Varela, 2003; Dierenfeld, 1996). Los animales fueron vermifugados con Levamisol 10 mg/kg (Martínez, 1994).

Para el sacrificio de los animales se utilizó la técnica descrita por Close, (1995) indicada para reptiles. La anestesia se realizo por administración intramuscular de Pentobarbital sódico a una dosis de $31,4 \mathrm{mg} / \mathrm{kg}$ (Moon y Hernández, 2001), 
posterior a lo cual se procedió a insertar una aguja afilada a través del foramen mágnum en la articulación atlantooccipital hasta la base del cerebro, para asegurar la rápida destrucción del mismo (Close, 1995).

La morfometría (Figura 1) se baso en las medidas propuestas por Medem en 1975 que consisten en: Longitud Recta de Caparazón (LRC), Longitud de Plastrón (LP), Longitud de la Sutura Media Ventral (SMV), Ancho de Caparazón (AC) y Peso (W). Se retiro el plastrón usando la técnica descrita y aplicada por Chacón (2001), también usada por Wyneken, (2001) y Faria, (2003) la cual consistió en cortar las uniones del puente, y luego incidir las uniones de piel con el peto, que después fue retirado realizando disección roma en dirección craneocaudal, al llegar a la zona pélvica con la ayuda de un martillo se fracturó el pubis ya que este se encontraba fusionado con el plastrón por ser una animal del suborden Pleurodirae (Rueda y Rueda, 2003).
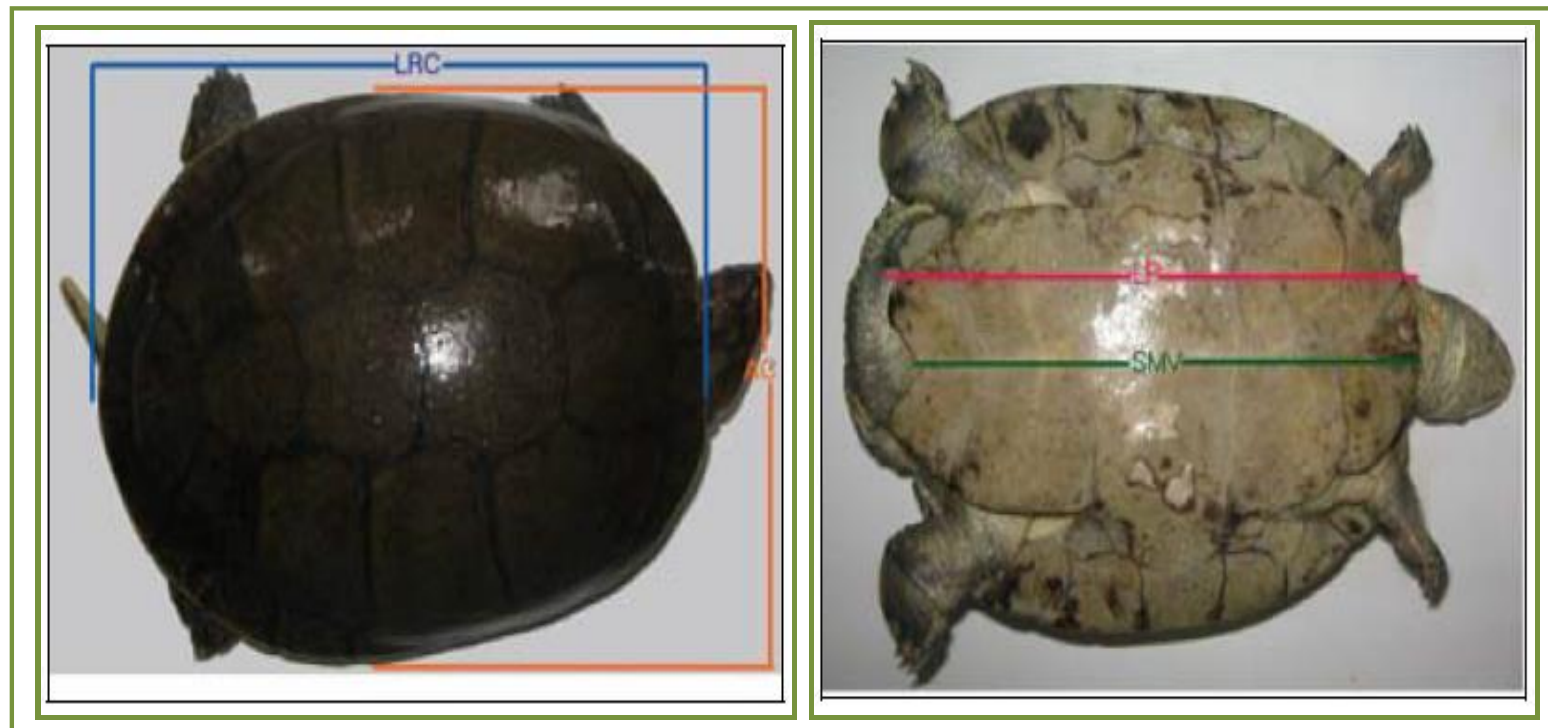

Figura 1. Morfometría: Longitud recta de Caparazón (LCR), Ancho de Caparazón (Ac), Longitud de plastrón (LP), Sutura media ventral (SMV).

Posteriormente se separó el paquete visceral del caparazón, para realizar registros fotográficos con cámara "Canon® AS400 Photoshot", en un cuarto oscuro a distancia de $40 \mathrm{~cm}$, consecutivamente se separaron los sistemas y se 
tomaron fotografías en las mismas condiciones anteriormente descritas. Luego de esto se midió cada uno de los órganos (longitud (craneocaudal), ancho (laterolateral) y peso), con los registros fotográficos se asignó un color para cada órgano teniendo como base la guía de colores de Microsoft ${ }^{\circledR}$, determinado por el programa ColorPic ${ }^{\circledR} 4.1$, esto para obtener los colores de referencias normales y distinguir estados patológicos por variación de estos.

Para el procesamiento histológico, las muestras se fijaron en formalina bufferada al $10 \%$, en una proporción $1: 10$, y se destinaron a cortes de 3-5 $\mu \mathrm{m}$ para microscopia de luz y teñidos con hematoxilina-eosina tradicional (Banks, 1996), realizadas en el Laboratorio de Patología de la Clínica Meta. Se realizaron fotomicrografías de las mismas láminas histológicas mediante microscopio "Leica GME y cámara Canon Photoshop A95".

\section{RESULTADOS Y DISCUSIÓN}

Los animales utilizados en esta investigación: las hembras tenían una longitud recta de caparazón (LRC) promedio de $26.47 \mathrm{~cm}$ y los machos $L R C$ de $19.11 \mathrm{~cm}$, lo cual difiere de lo planteado por Rueda y Rueda en 2003 que era de $23 \mathrm{~cm}$ para las hembras y 17 para los machos (Tablas 1, 2, 3, 4, 5 y 6). Esta diferencia se puede dar por origen de las tortugas y a sus condiciones alimenticias $y$ medioambientales de donde procedían (Claude, 2003). Los resultados a partir de la medición, observación y procesamiento de las diferentes estructuras y sistemas de especie estudiada permiten establecer de manera descriptiva y didáctica las siguientes consideraciones con respecto a lo encontrado a la literatura especializada, justificando las diferencias encontradas respecto a dicha literatura.

Sistema digestivo. El sistema digestivo inicia con un pico corneo, el cual abre a la cavidad orofaríngea, no se encuentra un estoma, ya que lo que simula la lengua son los cartílagos faríngeos y la extensión de hueso hioides. En la cavidad se abre la faringe, y el esófago (Figura 2). 
Esófago. Inicia en la cavidad orofaríngea, ubicado dorsal a la tráquea, en el plano medio del animal, está delimitado dorsalmente por los músculos cervicales, lateralmente por los músculos cervicales laterales y ventralmente por la tráquea. El esófago tiende a ubicarse ligeramente a la derecha del plano medio, en su última porción. Su forma es cilíndrica, presentando internamente en el primer tercio papilas (Figura 3 ) de forma piramidal de aproximadamente $3 \mathrm{~mm}$ de longitud, el segundo y tercer tercio se presenta con estriaciones cráneo-caudales. La porción caudal limita con el estomago.

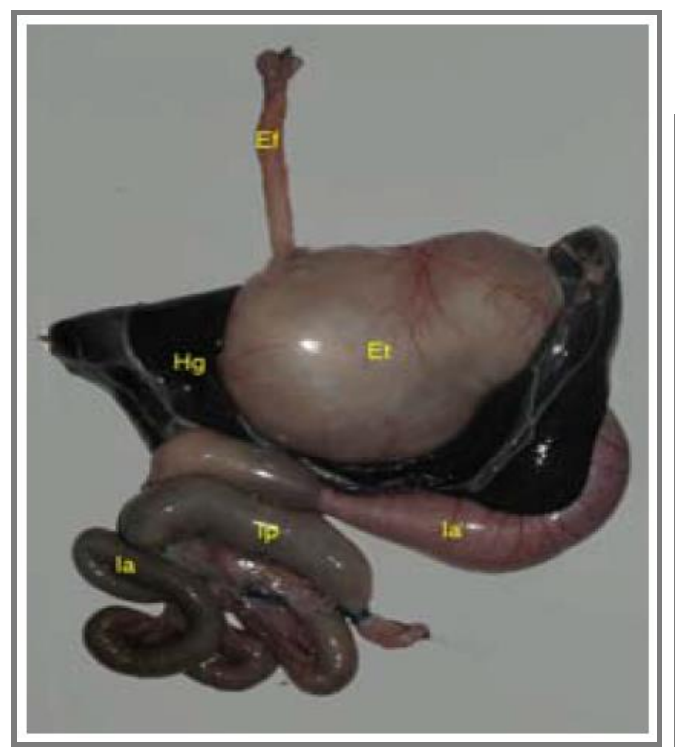

Figura 2. Ef: Esófago, Et: Estomago, Hg: Hígado, la: Intestino Anterior, Ip Intestino posterior

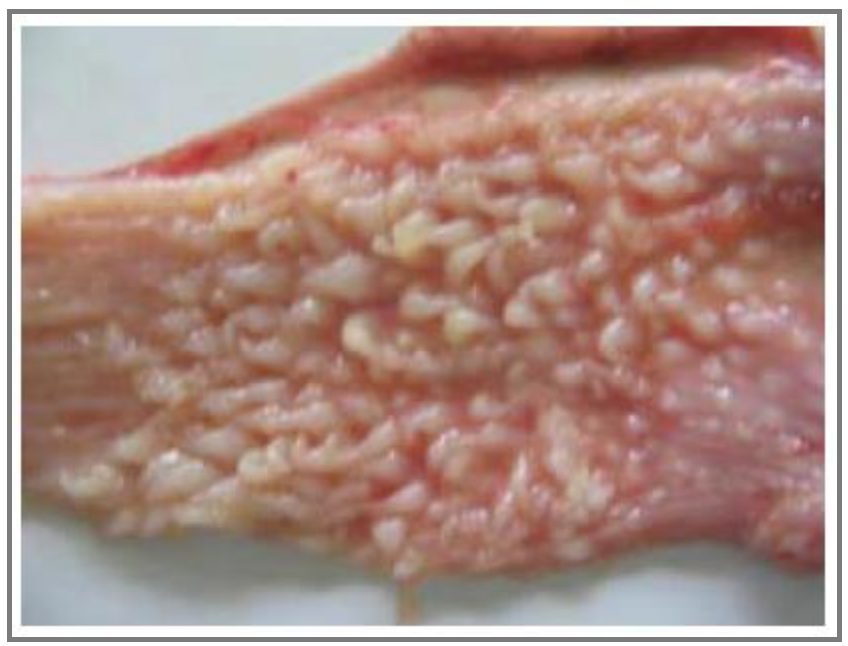

Figura 3. Papilas esofágicas

Histología del esófago. El esófago manifiesta dos zonas, la anterior (Figura 4), caracterizada por la presencia de las papilas esofágicas las cuales tienen una mucosa (Mc) con epitelio plano estratificado queratinizado (Ep); una submucosa (Smc) con tejido aerolar laxo, musculatura lisa (Msc) dispuesta en fibras longitudinales internas y circulares externas, y recubierta por una lamina serosa (S). La segunda porción del esófago (Figura 5) se constituye por una mucosa recubierta de un epitelio cilíndrico pseudoestretificado (Ec) acompañado de células caliciformes (Cc), con presencia de agregados linfoides $(L)$ en la submucosa, que se encuentra con tejido conjuntivo menos laxo a la porción papilar, las fibras 
musculares están dispuestas de la misma forma que en el esófago anterior. Se encuentra una serosa recubriendo el esófago.

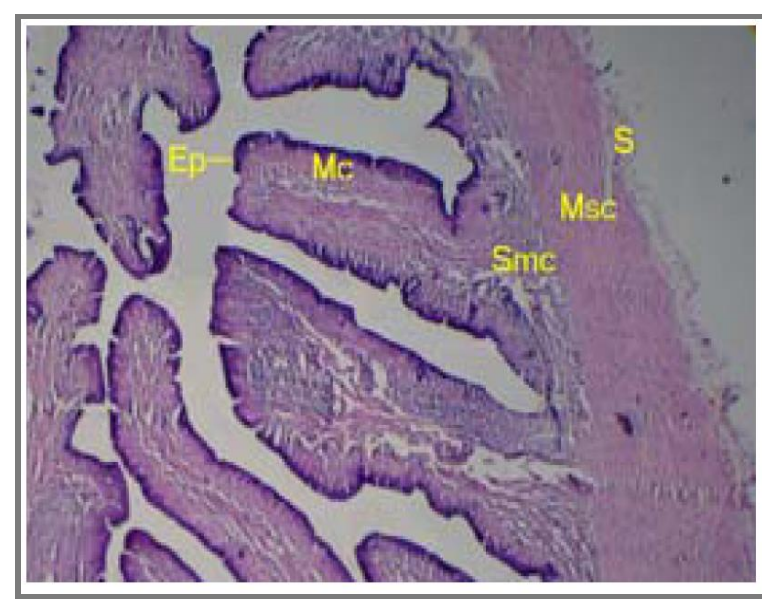

Figura 4. Corte histológico porción papilar del esófago (Aumento 4X).

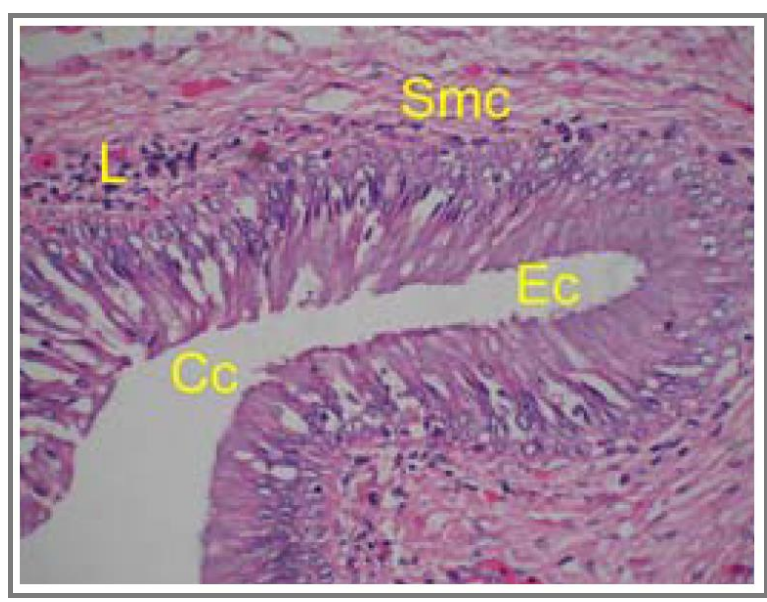

Figura 5. Corte histológico segunda porción del esófago (Aumento 40X).

Estómago. El estómago (Et) (Figura 2) cranealmente inicia en un cardias, ubicado a la izquierda del plano medio, el cual no se aprecia como un esfínter muscular. Tiene forma ovalada lo que no demuestra una curvatura mayor o menor. Dorsalmente está delimitado por los pulmones, y lateralmente por el hígado, ventralmente su porción anterior descansa sobre la membrana celomática y el plastrón, y su porción caudal sobre el hígado, caudalmente se encuentra el intestino anterior y el hígado. En la porción caudal derecha del plano medio en decúbito dorsal se encuentra el píloro sin la presencia de esfínter muscular donde inicia el intestino anterior. Internamente el estomago macroscópicamente no presenta diferencia en si mucosa, salvo algunas estriaciones.

Histología del estomago. Se encontraron dos porciones histológicamente, la anterior (Fúndica) (Figura 6 izquierda) caracterizada por una gruesa lamina mucosa (Mc) conformada por un epitelio cilíndrico simple, con una lámina basal diferenciada y con una muscular de la mucosa bien diferenciada, la submucosa (Smc) está compuesta por tejido denso irregular, con presencia de agregados linfoides cerca a los vasos sanguíneos, las fibras musculares (Msc) están 
organizadas en tres direcciones, la capa interna oblicua, la media circular y la externa longitudinal, esta última en contacto con la serosa (S).

La segunda porción (pilórica) (Figura 6 derecha) posee una mucosa con epitelio cilíndrico (Ec) pero menos amplia que la porción anterior, bajo el epitelio tiene una lámina propia de la mucosa $(\mathrm{Lpm})$ conformada por tejido areolar laxo y células linfoides $(\mathrm{Cl})$, que se separa de la submucosa $(\mathrm{Smc})$ por una lamina muscular de la mucosa, la submucosa y la muscular (Msc) se disponen de la misma forma que la porción anterior, al igual que la serosa.
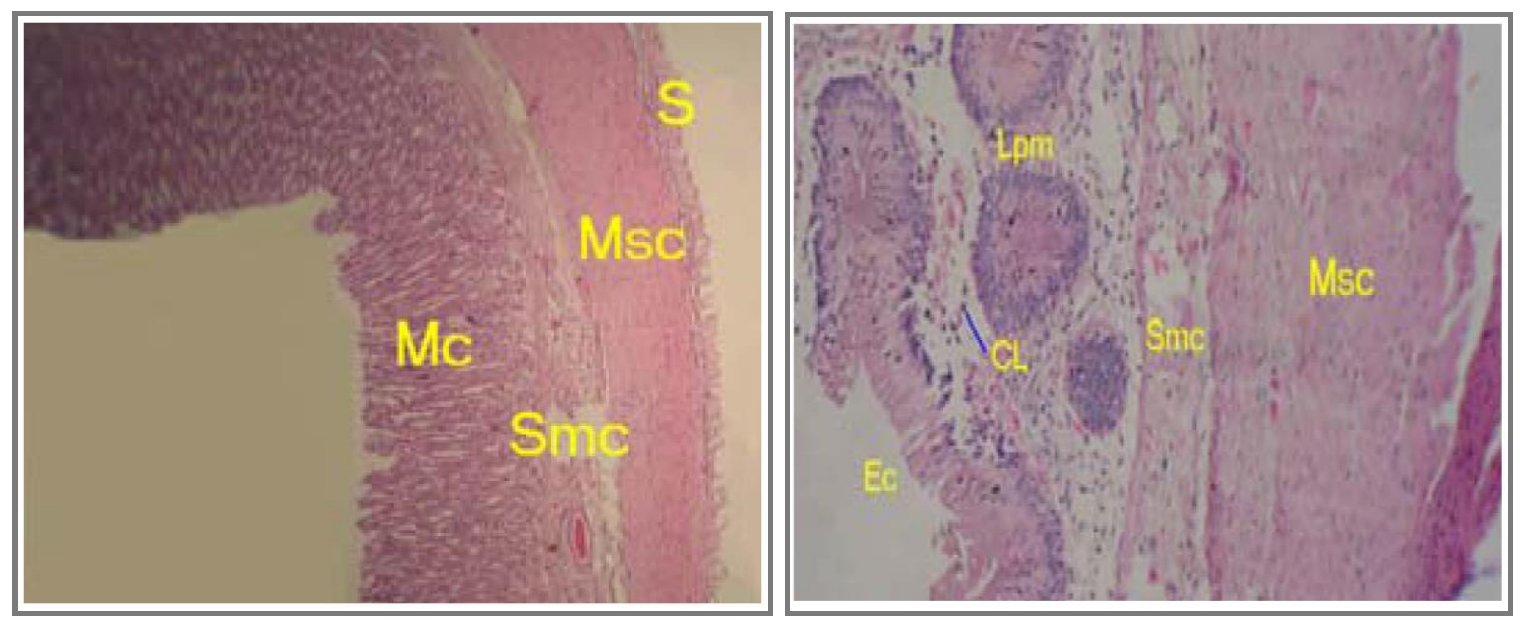

Figura 6. Cortes histológicos de estómago; porción fúndica (izquierda) y porción pilórica (derecha)

Hígado. La mayor parte del hígado (Figura 7) se encuentra al lado derecho, en el tercio medio de la cavidad celómica, sus extremos laterales están embebidos entre los puentes, se observan cuatro divisiones, la primera derecha (LD), la cual se encuentra en contacto con el pulmón derecho y con la porción derecha del estómago, se caracteriza por ser el más grande de los cuatro lóbulos hepáticos, la segunda porción accesoria ( $\mathrm{LACC}$ ), se encuentra caudal al lóbulo derecho en contacto con el intestino anterior, los lóbulos restantes se caracterizan por reducir su perímetro en la región media de la cavidad celomática para darle cabida al estomago y se alargan nuevamente para introducirse en el puente izquierdo, estos se diferencian por ser uno parietal (LIP) y otro visceral (LIV). 


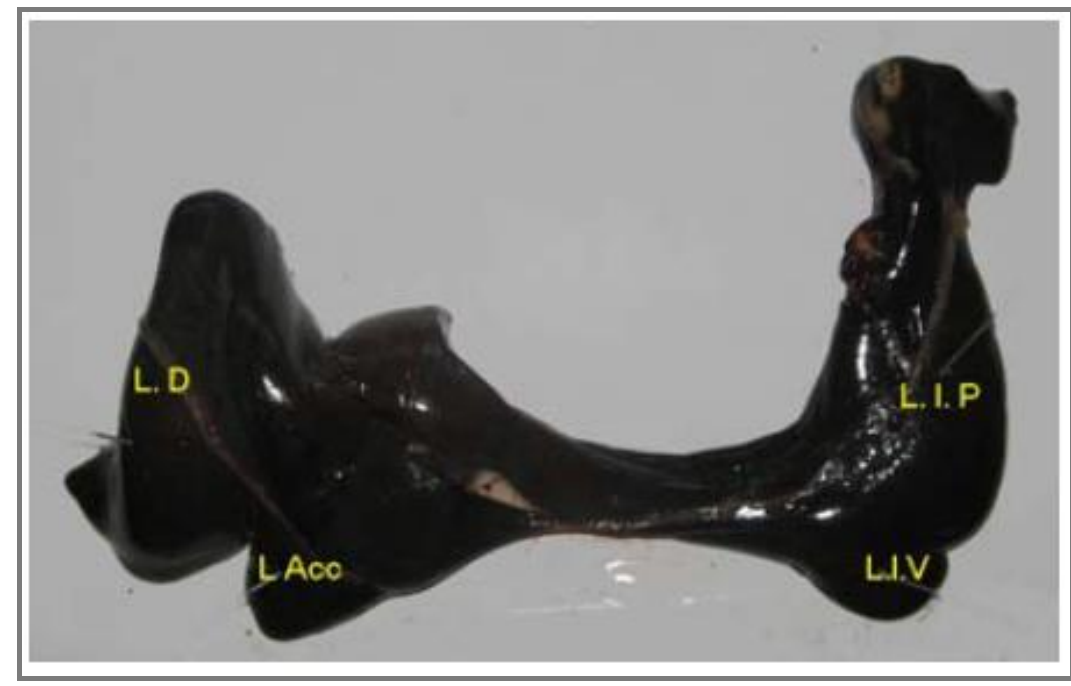

Figura 7. Vista ventral del hígado. L.D: Lóbulo derecho; LAcc: Lóbulo accesorio; LIV: Lóbulo izquierdo visceral; LIP: Lóbulo izquierdo parietal.

La parte craneal del hígado está delimitada por el puente en la porción derecha en el plano sagital por el estomago y por el puente izquierdo, dorsalmente está en contacto con el estomago, los pulmones, la vesícula biliar y el colédoco, ventralmente con la membrana celomática y así con los músculos abdominales ventrales, y la porción caudal se encuentra en contacto con el duodeno y con el intestino posterior.

Histología del hígado. En el corte del hígado (Figura 8), los hepatocitos se encuentran organizados en cordones radiados, hacia una vena $(\mathrm{Vn})$, recubiertos de tejido conectivo interlobulillar, se localiza la triada portal formada por una arteria $(\mathrm{Ar})$, una vena $(\mathrm{Vn})$ y un conducto hepático $(\mathrm{Ch})$, una característica predominante es la presencia de pigmentos (melanina) anexos a los vasos sanguíneos, depositados por los melanomacrófagos (Mn).

Colédoco. El conducto colédoco (Co) (Figura 9), de forma cilíndrica, está ubicado dorsalmente al hígado, adherido en su primer cuarto a este, se encuentra ente los lóbulos derecho (LD) y accesorio (LAcC) del hígado, delimitándose cranealmente con la vesícula biliar (VB), lateralmente y ventralmente con el hígado, su ubicación 
es a la derecha del plano medio, caudalmente delimitada con el intestino anterior (la), insertándose en el primer séptimo de este.
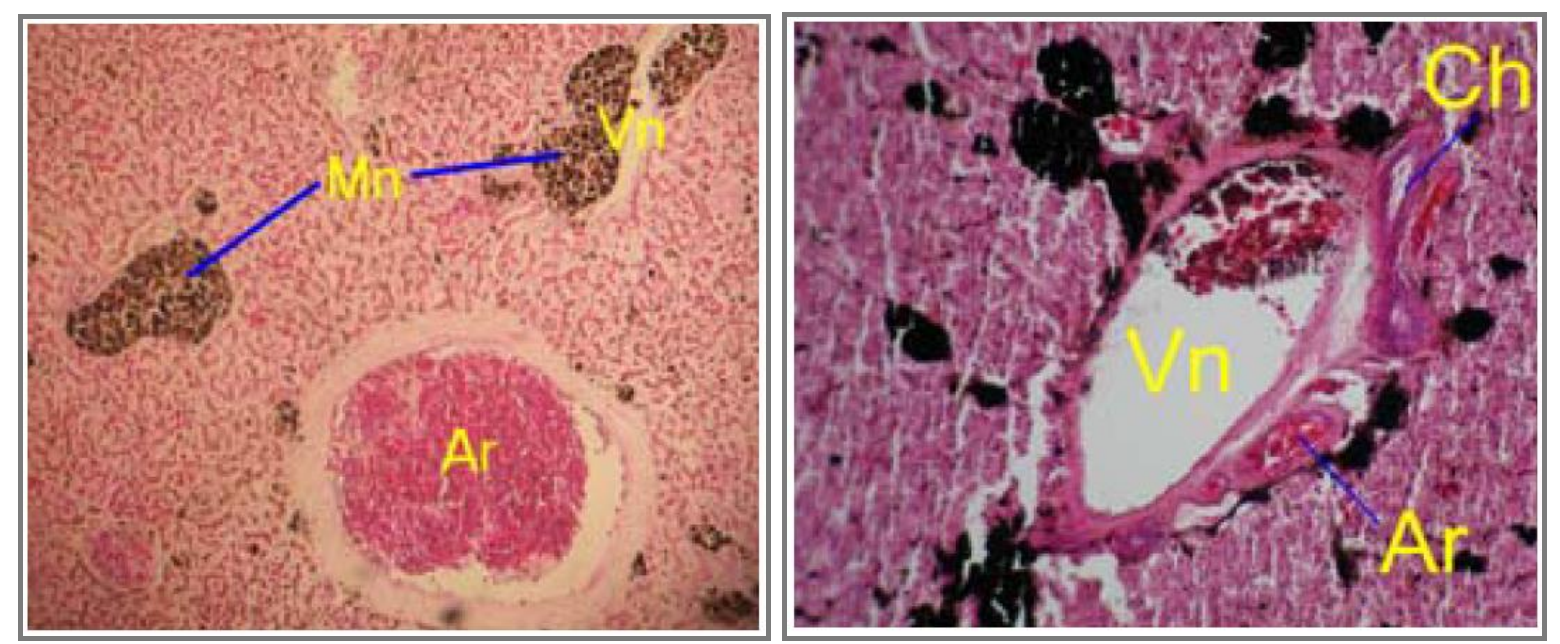

Figura 8. Corte histológico de hígado; Melanomacrófagos y arteriola hepática (izquierda); Triada portal (derecha)

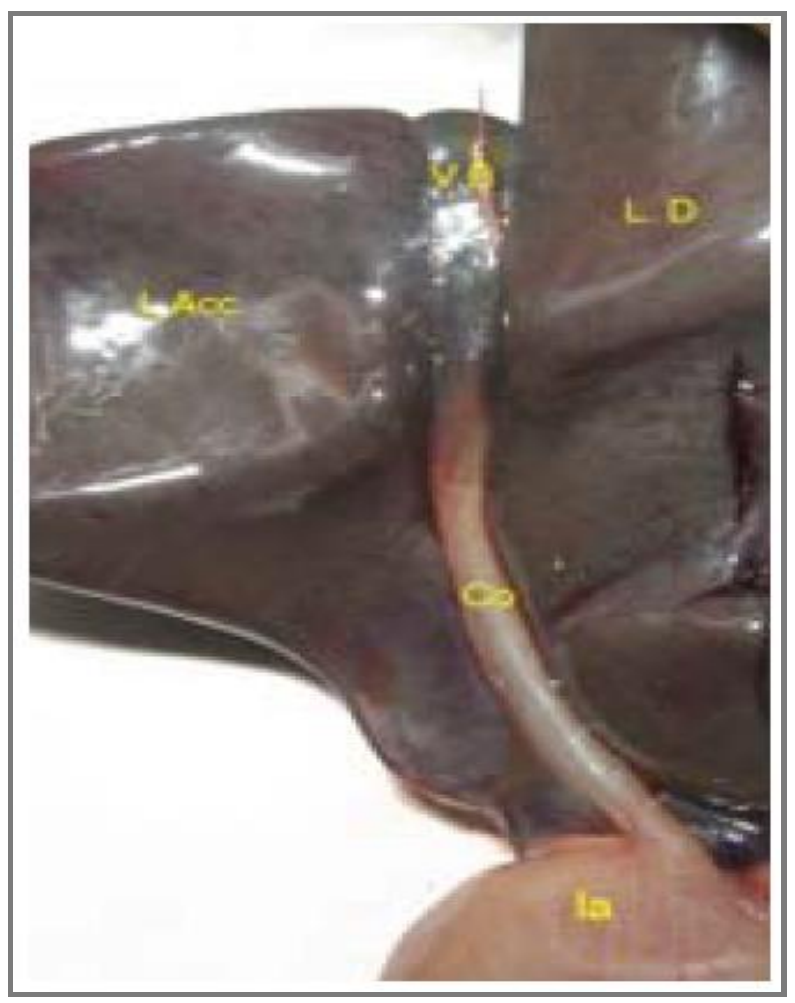

Figura 9. VB: Vesícula biliar; Lacc: Lóbulo accesorio; LD: Lóbulo derecho; Co: Colédoco; la: Intestino anterior. 
Histología del colédoco. El colédoco (Figura 10) tiene una mucosa caracterizada por un epitelio cilíndrico simple (Ec), sustentando sobre una lamina propia (Lp) que presenta varios conductos y células linfoides. La submucosa $(\mathrm{Smc})$ conformada por tejido conectivo denso irregular, alberga agregados linfoides, la lamina muscular lisa (Msc) está organizada por paquetes musculares circulares principalmente, y finalmente se recubre con una túnica serosa (Se).

Vesícula biliar. La vesícula biliar (VB) (Figura 9) se encuentra topográficamente ubicada dorsal a la unión de los lóbulos derecho (LD) y accesorio (LAcC) del hígado, a la derecha del plano medio, íntimamente adherida a este órgano, su borde craneal se relaciona con el estómago, y su parte caudalmente se encuentra unida al conducto colédoco (Co).

Histología de vesícula biliar. La arquitectura de la vesícula biliar (Figura 11) está conformada por una mucosa, con un epitelio cilíndrico pseudoestretificado (Ep), al igual que la submucosa $(\mathrm{Smc})$ se encuentra con agregados linfoides (Al), cubiertas por una gruesa capa muscular (Msc) y por último una serosa, el tejido vesical se aprecia con pliegues ya que se encuentra relajado, es decir sin contenido biliar.

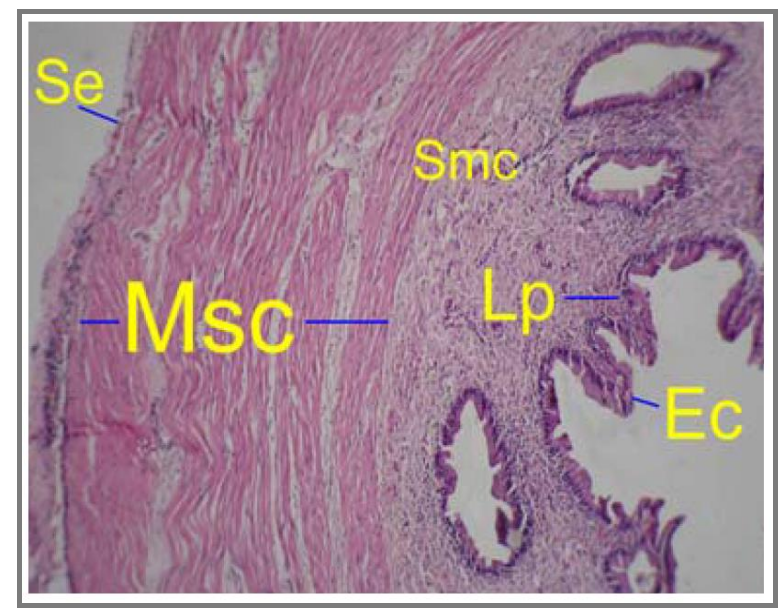

Figura 10. Corte histológico del colédoco

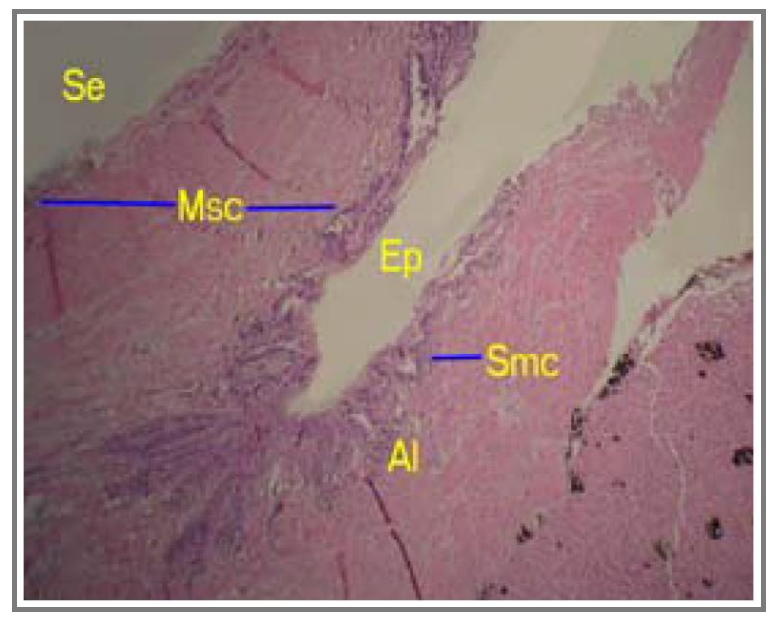

Figura 11. Corte histológico de vesícula biliar

Páncreas. El páncreas ( $\operatorname{Pr}$ ) (Figura 12) se encuentra en posición craneal del tercer séptimo del intestino anterior, adherido íntimamente a este, impidiendo observar 
los conductos pancreáticos (CP), sus limitantes son el intestino anterior, su forma es cónica con invaginaciones, situándose la base de este en la porción derecha de la cavidad celómica y el ápice hacia la línea media del animal.
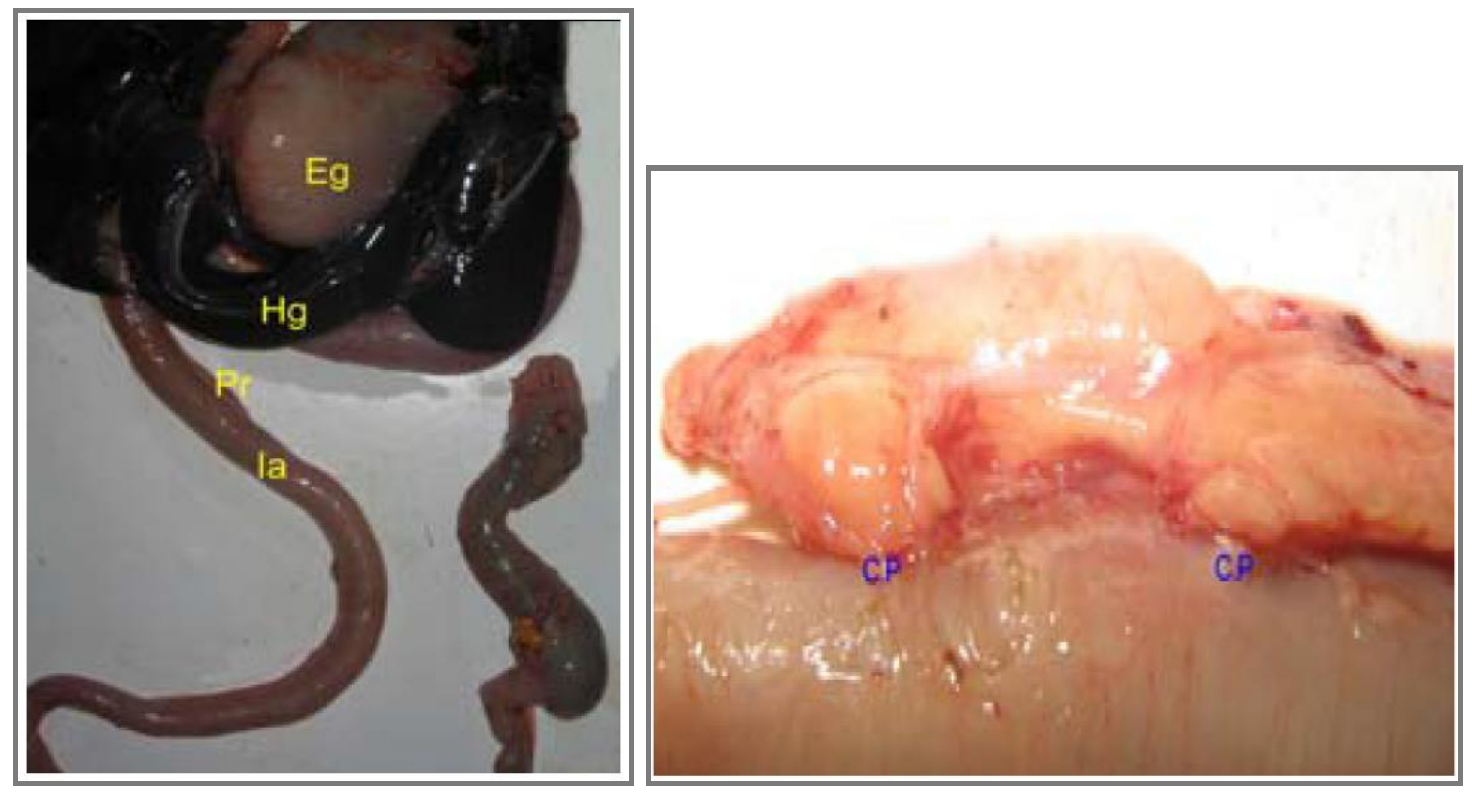

Figura 12. Izquierda: Páncreas (Pr); Intestino anterior (la); Hígado (Hg); Estómago (Eg). Derecha: Conducto Pancreáticos (CP).

Histología de páncreas. El páncreas es un órgano parenquimatoso (Figura 13), está conformado por dos zonas una cortical $(\mathrm{Cz})$ y una medular (Md), en las cuales se encuentran islotes (Ip) y acinos (Acp) pancreáticos, con células centroacinares (Cca) y conductos pancreáticos, acompañados de conductos interlobulillares y vasos sanguíneos.

Intestino anterior. El intestino anterior (la) (Figura 2) se encuentra ubicado caudal al hígado y al estomago distribuido en la cavidad celómica, estando la mayoría inclinado hacia la derecha de la cavidad, su parte dorsal limita con los pulmones y riñones, lateralmente con los ovarios y los oviductos en las hembras, y en los machos con las paredes celómicas, la porción caudal limita con la vejiga urinaria y con las bolsas cloacales, y ventralmente con el plastrón. Su forma se caracteriza por ser cilíndrica siendo el primer séptimo de mayor calibre, el cual se une cranealmente al estomago en el píloro, a la izquierda del plano medio, posterior a 
esto se dirige hacia la región derecha de la cavidad, donde vira en forma de asa para alojar el páncreas, posteriormente realiza una serie de sigmas para alojarse en el intestino posterior en una porción dorsal de la cavidad.

Histología de intestino anterior. El intestino anterior (Figura 14) presenta una mucosa (Mc) con epitelio cilíndrico simple con presencia de células caliciformes, esta se soporta en la muscular de la mucosa, esta forma vellosidades relativamente cortas, la submucosa $(\mathrm{Smc})$ alberga glándulas y se aprecian criptas (Lieberkühn), allí se aprecian agregados linfoides, es seguida de dos laminas musculares (Msc) una interna y otra externa, recubiertas por una serosa (S).

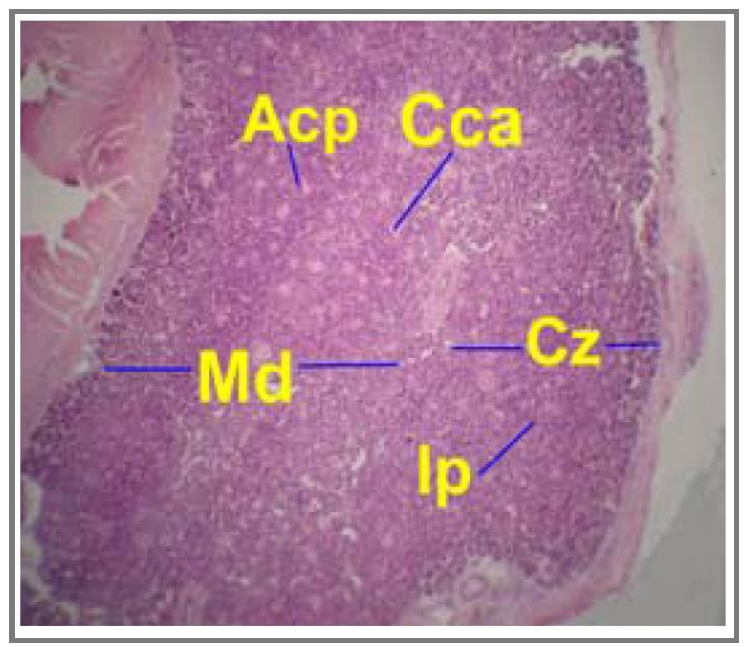

Figura 13. Corte histológico del páncreas $4 \mathrm{X}$

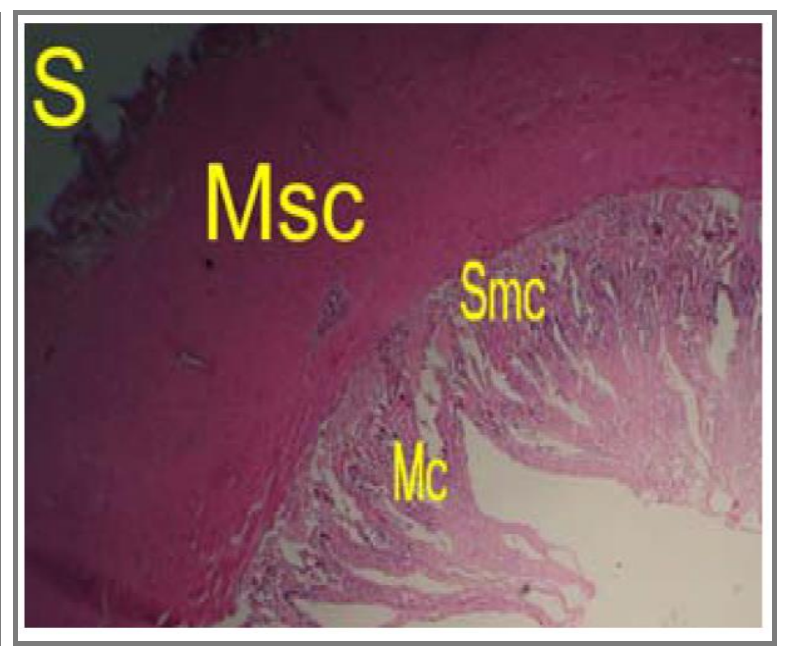

Figura 14. Corte histológico del Intestino

Intestino posterior. El intestino posterior (Ip) (Figura 2) se encuentra en la línea media de la cavidad celomática, iniciando dorsalmente en el intestino anterior y ubicándose bajo la porción posterior de los pulmones, para dirigirse caudalmente hasta la cloaca donde desemboca. Inicia con una dilatación en forma de bolsa mas no en un ciego, ya que no posee unas válvulas delimitadas, posteriormente se disminuye su calibre para por último dilatarse nuevamente antes de ingresar en la cloaca.

Histología del intestino posterior. La mucosa del intestino posterior (Figura 15) se caracteriza por tener unas vellosidades poco prominentes, cubierta por un 
epitelio cilíndrico (Ec) simple acompañado de células linfoides, soportadas en una lamina muscular de la mucosa (Ms $\mathrm{M}$ ), la submucosa (Smc) está formada por tejido conectivo denso irregular, con agregados linfoides, la capa muscular (Ms) es de menor calibre a la presente en el intestino anterior, sin una orientación definida de sus fibras, también está presente una capa serosa.

Tabla 1. Morfometría sistema digestivo

\begin{tabular}{cccc}
\hline Órgano & Largo (cm) & Ancho (cm) & Peso (gr) \\
\hline Esófago & $9,12 \pm 1,77$ & $0,9 \pm 0,18$ & $4,25 \pm 2,04$ \\
Estómago lleno & $5,85 \pm 1,98$ & $7,99 \pm 2,21$ & $64,67 \pm 42,52$ \\
Estómago vacío & $6,22 \pm 1,86$ & $8,31 \pm 2,31$ & $19,61 \pm 9,58$ \\
Hígado & $9,32 \pm 1,48$ & $15,99 \pm 3,03$ & $85,78 \pm 43,48$ \\
Colédoco & $2,91 \pm 0,87$ & $0,34 \pm 0,11$ & $0,26 \pm 0,18$ \\
Vesícula biliar & $3,08 \pm 0,62$ & $0,95 \pm 0,39$ & $1,36 \pm 0,92$ \\
Páncreas & $5,32 \pm 1,46$ & $0,98 \pm 0,25$ & $1,26 \pm 0,77$ \\
Intestino anterior lleno & $70,79 \pm 19,49$ & $1,15 \pm 0,28$ & $42,90 \pm 26,86$ \\
Intestino anterior vacío & $70,76 \pm 19,51$ & $1,15 \pm 0,28$ & $28,80 \pm 13,22$ \\
Intestino posterior & $11,40 \pm 3,22$ & $1,88 \pm 0,59$ & $7,41 \pm 4,06$ \\
\hline
\end{tabular}

Tabla 2. Relación porcentual alométrica sistema digestivo

\begin{tabular}{cccccc}
\hline Órgano & $\begin{array}{c}\text { L/LRC } \\
(\%)\end{array}$ & $\begin{array}{c}\text { L/Plastrón } \\
(\%)\end{array}$ & $\begin{array}{c}\text { L/SMV } \\
(\%)\end{array}$ & $\begin{array}{c}\text { AnO/An } \\
(\%)\end{array}$ & $\begin{array}{c}\text { PO/Pan } \\
(\%)\end{array}$ \\
\hline Esófago & $36,30 \pm 3,98$ & $44,14 \pm 4,37$ & $46,16 \pm 5,02$ & $5,41 \pm 1,31$ & $0,27 \pm 0,05$ \\
Estómago lleno & $25,47 \pm 6,09$ & $28,05 \pm 6,69$ & $29,32 \pm 7$ & $52,71 \pm 10,76$ & $4,69 \pm 2,88$ \\
Estómago vacío & $27,03 \pm 4,68$ & $29,74 \pm 5,09$ & $31,08 \pm 5,35$ & $49,67 \pm 11,58$ & $1,29 \pm 0,31$ \\
Hígado & $41,26 \pm 5,40$ & $45,47 \pm 6,57$ & $47,55 \pm 7,22$ & $94,56 \pm 4,49$ & $5,37 \pm 0,57$ \\
Colédoco & $12,76 \pm 3,22$ & $14,05 \pm 3,59$ & $14,68 \pm 3,77$ & $1,99 \pm 0,45$ & $0,02 \pm 0,01$ \\
Vesícula biliar & $13,65 \pm 2,54$ & $15,04 \pm 2,89$ & $15,74 \pm 3,23$ & $5,52 \pm 1,72$ & $0,08 \pm 0,04$ \\
Páncreas & $23,13 \pm 3,48$ & $25,45 \pm 3,74$ & $26,60 \pm 3,96$ & $5,74 \pm 1,25$ & $0,07 \pm 0,03$ \\
Intestino ant. lleno & $311,08 \pm 62,61$ & $340,29 \pm 70,5$ & $354,03 \pm 74,43$ & $6,89 \pm 0,85$ & $2,53 \pm 1,06$ \\
Intestino ant. vacío & $310,30 \pm 62,94$ & $341,56 \pm 69,52$ & $356,85 \pm 72,42$ & $6,76 \pm 0,83$ & $1,86 \pm 0,34$ \\
Intestino posterior & $49,71 \pm 9,05$ & $54,64 \pm 9,68$ & $57,14 \pm 10,39$ & $11,15 \pm 3,18$ & $0,48 \pm 0,18$ \\
\hline L/LRC: Largo del órgano / Longitud Recta de Caparazón * 100; L/Plastrón: Largo órgano / Longitud \\
de Plastrón; L/SMV: Largo órgano / Sutura Media Ventral; AnO/An: Ancho órgano /Ancho animal * \\
100; PO/Pan: Peso órgano / Peso animal * 100 \\
El sistema digestivo se caracterizó por poseer arquitectura similar a la descrita en \\
otros reptiles, manteniendo el patrón del tubo digestivo, conformado por túnicas \\
mucosas, submucosa, muscular y el recubrimiento por una capa serosa (Chacón, \\
2001; Oros, 2004). Una cualidad permanente es la presencia de tejido linfoide
\end{tabular}


ubicado en las túnicas mucosa y submucosa, el cual cumple la función de ser la tercera barrera inmunitaria después del moco y el epitelio (Banks, 1996), también se observa una orientación definida de sus fibras y una capa serosa.

La notable división del esófago en dos secciones con características histológicas y morfológicas distintas se encuentra directamente relacionado con su función, ya, que las papilas con su epitelio plano estratificado queratinizado y su musculatura recubierta por la capa serosa en la primera zona, están directamente relacionadas con funciones mecánicas que favorecen el transporte del bolo alimenticio. Por otro lado, el epitelio cilíndrico ciliado pseudoestratificado, las células caliciformes y los agregados linfoides en la submucosa de la segunda zona (Chacón, 2001; Oros, 2004), se encuentran involucrados con funciones particulares de equilibrio osmótico y barreras inmunitarias.

Respecto a la distribución uniforme del estómago en la cavidad celómica, se difiere con lo reportado por Oros, (2004) quien reporta su ubicación a la izquierda; por otro lado, se encuentra similitud a lo sugerido por Chacón, (2001) respecto a la no presencia del marco plicatus. En el estudio histológico se vislumbraron dos porciones diferenciadas por su mucosa, lo cual no concuerda con lo planteado por Oros, (2004) ya que se encontró epitelio plano característico de la región cardial manteniéndose las regiones fúndica y pilórica.

El intestino anterior, posee una longitud que corresponde al 311,08 $\pm 62,21 \%$ de la LRC lo cual difiere de lo descrito por Oros, (2004) para tortugas marinas, quien plantea que es de escasa longitud, lo cual es justificable según los hábitos alimenticios de la especie (Rueda y Rueda, 2003). Se encontraron similitudes en la organización de los tejidos, aunque se determinó de manera específica las divisiones del intestino anterior.

El hígado se presentó como un órgano de gran tamaño representando el 41,26 \pm $5,4 \%$ de la LRC, el $94,56 \pm 4,49 \%$ del ancho y $5,377 \pm 0,57 \%$ del peso (Tablas 1 y 2), lo que fortalece lo descrito por Chacón, (2001) para la tortuga terecay, pero a diferencia de este autor, los resultados de este estudio indicaron que este órgano 
era tetralobulado y no bilobulado. La presencia de melanomacrofagos y cúmulos de melanina podría estar relacionado con la inmunidad celular que se describe para peces y anfibios como respuesta a lesiones tisulares (Haugarvoll, 2004), o a la destrucción, detoxificación o reciclaje de materiales endógenos o exógenos, incluyendo agentes infecciosos (Vogelbein et al., 1987; Haaparanta et al., 1996), ninguno de estos autores caracterizó el colédoco, aporte que se da en el presente trabajo.

La vesícula biliar se encontró ubicada entre los lóbulos derecho y accesorio, aportando a lo descrito por Chacón, (2001) no se encontraron diferencias de la conformación histológica, con las reportadas con este autor, siendo un epitelio cilíndrico pseudoestratificado, lo cual es compatible con su función de transporte de las sustancias biliares (Banks, 1996).

El páncreas esta adosado al intestino teniendo no un conducto (Wyneken, 2001) sino dos (Slack, 1995; Kardong, 1999), y no se encuentra unido al bazo (Oros, 2004), fortaleciendo lo descrito por Chacón, (2001) se observaron islotes pancreáticos. El intestino posterior, no presentó divisiones macroscópicas notables (Oros, 2004), ni cintas cólicas (Wyneken, 2001).

\section{Sistema respiratorio}

El sistema respiratorio (Figura 16) se inicia en las narinas externas, la parte posterior ingresa por las internas a la orofaringe, donde en su base se encuentran las estructuras faríngeas $(\mathrm{Fg})$, y donde se abre la tráquea $(\mathrm{Tr})$ en la glotis.

Tráquea. (Tr) (Figura 16) Inicia al finalizar los cartílagos faríngeos y laríngeos (Cricoides, Tiroides y Aritenoides) como un tubo cilíndrico de anillos cartilaginosos, se ubica ventral al esófago, lateral y dorsal a los músculos cervicales y se dirige dorsocaudalmente al entrar en contacto con el estomago, se bifurca en los bronquios a nivel de las ultimas vertebras cervicales.

Histología de la tráquea. La tráquea (Figura 17) está conformada en su mucosa por un epitelio cilíndrico pseudoestratificado ciliado (Ep) con presencia de células 
caliciformes (Cc), se halla una delgada capa muscular de la mucosa (Ms $M$ ), seguido de una capa de cartílago hialino, posteriormente se encuentra una capa de musculatura lisa (MSC), y finalmente se percibe una túnica serosa (S).

Bronquios. (Br) (Figura 16) Son dos tubos anillados cartilaginosos, que nacen en la bifurcación traqueal y se insertan en los pulmones, ubicados dorsalmente al estómago, en contacto lateral con los arcos aórticos y ventral con el corazón.
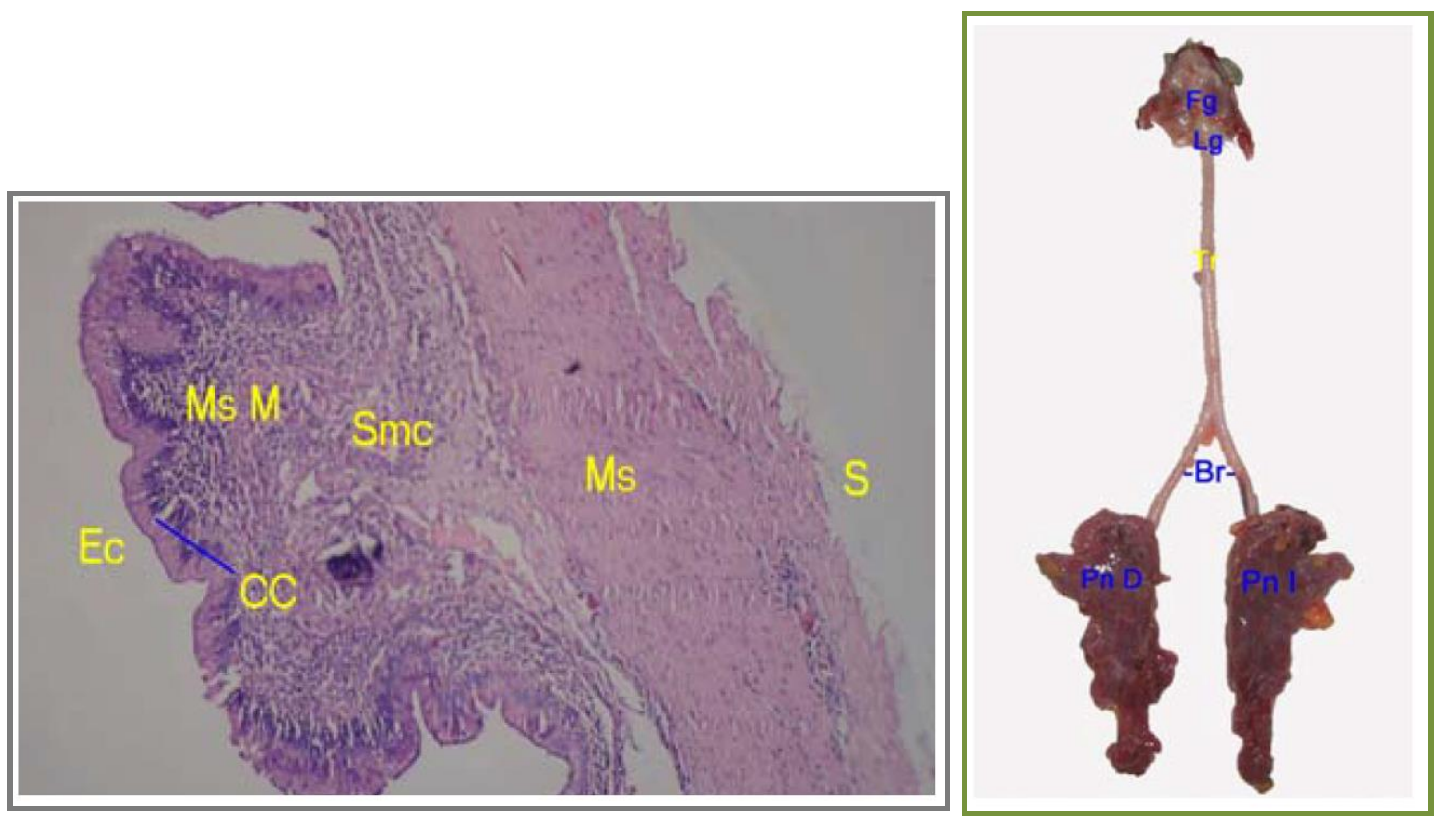

Figura 15. Corte histológico Intestino posterior $10 \mathrm{X}$
Figura 16. Lg: Laringe; Fg: Faringe; Tr: Tráquea; $\mathrm{Br}$ : Bronquios; PnD: Pulmón derecho; Pnl: Pulmón izquierdo

Histología de bronquios. Los bronquios (Figura 18) histológicamente son similares a la tráquea con la diferencia que estos poseen una zona en la cual el cartílago hialino $(\mathrm{Ch})$ no cubre completamente la circunferencia bronquial y allí se aloja musculatura lisa (LM).

Pulmones. Los pulmones (Pn) (Figura 16) inician en los bronquios en el primer tercio de la cavidad celomática, se despliegan hasta el inicio de primer tercio de la misma. La parte dorsal de estos órganos están adheridos al caparazón, la lateral y caudal están en contacto con los puentes, hasta cubrir los riñones, ventralmente su zona anterior está en contacto a la derecha del hígado, y a la izquierda con el estómago, su porción media entra en contacto con los mesenterios y su porción 
posterior con los riñones y con las gónadas. La fracción más craneal, y la mas caudal modifican su parénquima siendo menos denso, simulando un enfisema.

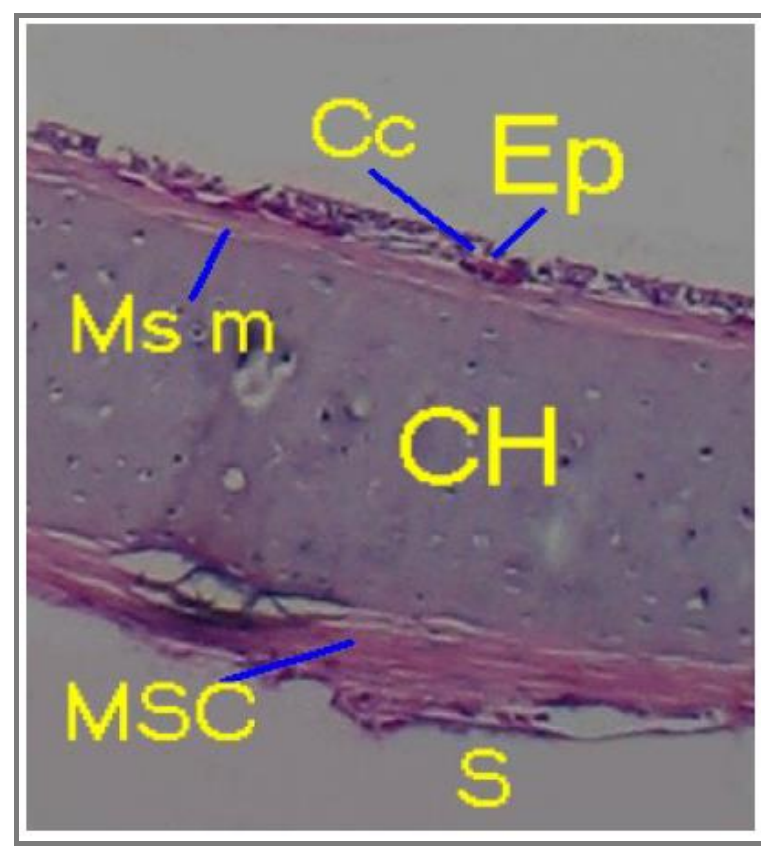

Figura 17. Corte histológico de tráquea $40 \mathrm{X}$

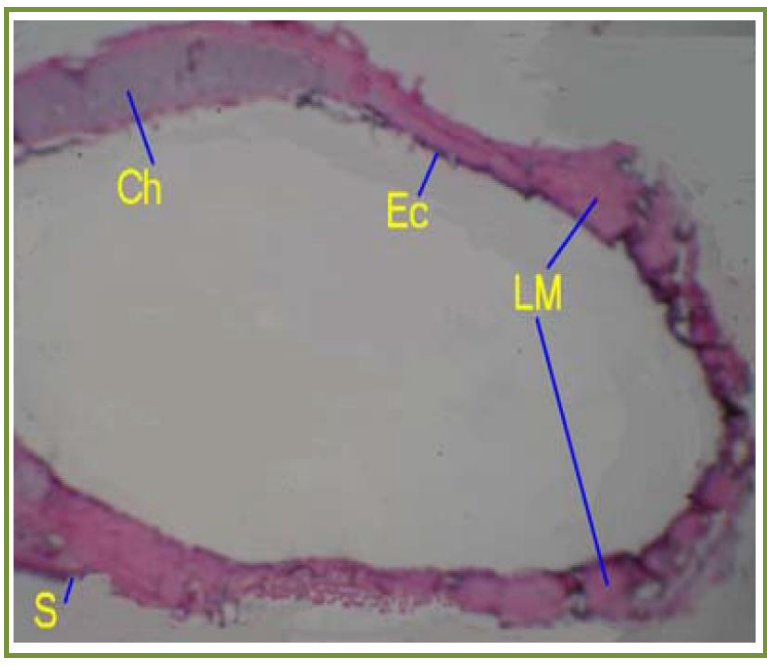

Figura 18. Corte histológico de bronquio $4 \mathrm{X}$

Histología del pulmón. Los pulmones poseen estructuras de intercambio gaseoso amplias, los faveolos (Fv) (Figura 19), en los cuales se encuentra un epitelio plano simple (Ep), circundado por poco tejido interfaveolar conectivo denso irregular (Tc), acompañado de fibras musculares lisas (MI), en algunas porciones se aprecia cartílago hialino (Ch). Dentro de los pulmones se observan los bronquiolos $(\mathrm{Brl})$ con epitelio cubico simple. Es notable en el primer corte, alta presencia de células eritrocitarias y en el segundo de tejido vascular.

Tabla 3. Morfometría sistema respiratorio

\begin{tabular}{cccc}
\hline Órgano & Largo $(\mathbf{c m})$ & Ancho $(\mathbf{c m})$ & Peso $(\mathbf{g r})$ \\
\hline Tráquea & $7,76 \pm 1,37$ & $0,54 \pm 0,09$ & $0,65 \pm 0,25$ \\
Bronquio derecho & $4,08 \pm 1,02$ & $0,45 \pm 0,07$ & $0,24 \pm 0,13$ \\
Bronquio izquierdo & $4,12 \pm 0,66$ & $0,47 \pm 0,09$ & $0,22 \pm 0,16$ \\
Pulmón derecho & $10,70 \pm 2,33$ & $3,93 \pm 0,71$ & $9,76 \pm 5,38$ \\
Pulmón izquierdo & $10,44 \pm 2,31$ & $4,00 \pm 1,15$ & $9,57 \pm 4,81$ \\
\hline
\end{tabular}



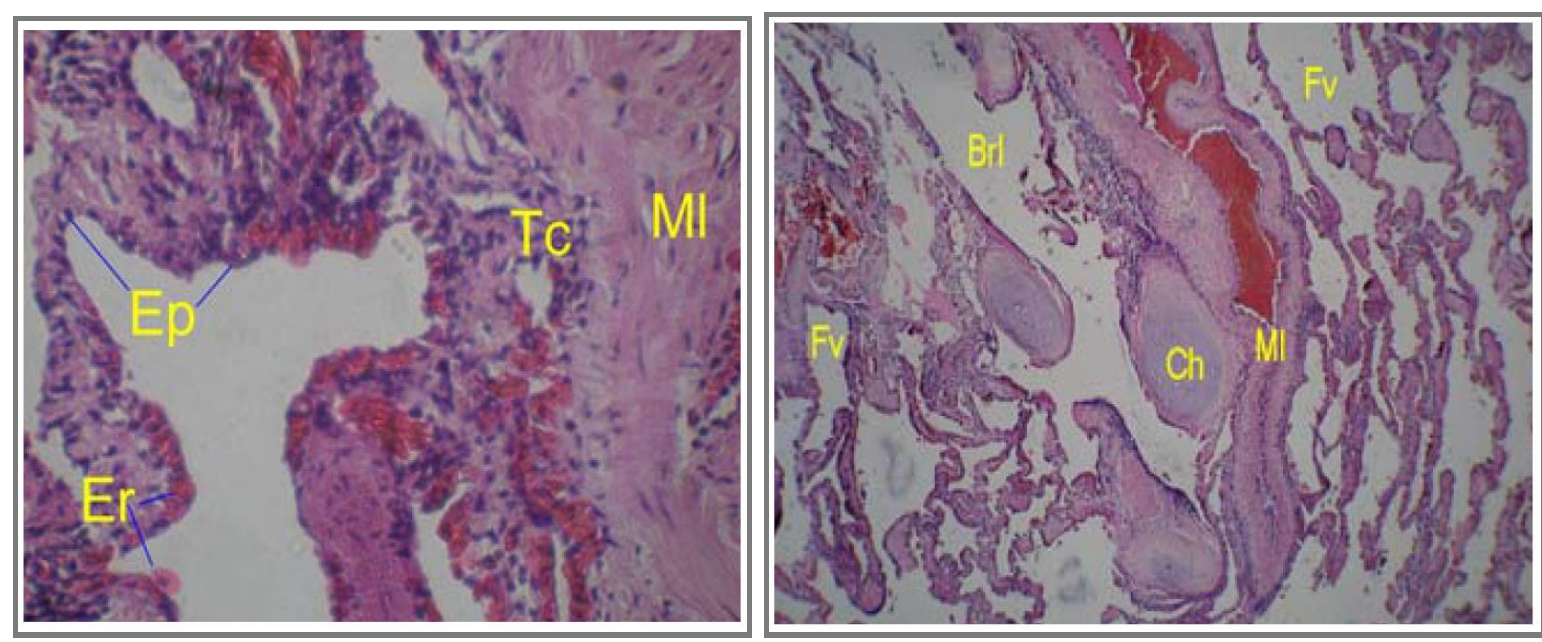

Figura 19. Cortes histológicos de pulmón. Derecha: Flaveolo 40X. Izquierda: parénquima pulmonar.

Tabla 4. Relación porcentual alométrica sistema respiratorio

\begin{tabular}{cccccc}
\hline Órgano & $\begin{array}{c}\text { L/LRC } \\
\text { (\%) }\end{array}$ & $\begin{array}{c}\text { L/Plastrón } \\
\text { (\%) }\end{array}$ & $\begin{array}{c}\text { L/SMV } \\
\text { (\%) }\end{array}$ & $\begin{array}{c}\text { AnO/An } \\
\text { (\%) }\end{array}$ & $\begin{array}{c}\text { PO/Pan } \\
\text { (\%) }\end{array}$ \\
\hline Tráquea & $34,07 \pm 1,47$ & $37,52 \pm 2,25$ & $39,22 \pm 2,7$ & $3,26 \pm 0,56$ & $0,05 \pm 0,02$ \\
Bronquio derecho & $17,73 \pm 2,06$ & $19,50 \pm 2,13$ & $20,37 \pm 2,22$ & $2,69 \pm 0,53$ & $0,02 \pm 0,01$ \\
Bronquio izquierdo & $18,15 \pm 1,09$ & $19,98 \pm 1,48$ & $20,90 \pm 1,78$ & $2,85 \pm 0,73$ & $0,02 \pm 0,01$ \\
Pulmón derecho & $47,43 \pm 7,87$ & $52,15 \pm 8,55$ & $54,54 \pm 9,29$ & $23,76 \pm 5,17$ & $0,61 \pm 0,12$ \\
Pulmón izquierdo & $45,99 \pm 7,55$ & $50,59 \pm 8,31$ & $52,93 \pm 9,15$ & $23,40 \pm 4,1$ & $0,61 \pm 0,11$ \\
\hline
\end{tabular}

L/LRC: Largo del órgano / Longitud Recta de Caparazón * 100; L/Plastrón: Largo órgano / Longitud de Plastrón; L/SMV: Largo órgano / Sutura Media Ventral; AnO/An: Ancho órgano /Ancho animal * 100; PO/Pan: Peso órgano / Peso animal * 100

La tráquea de la especie estudiada representa el $34,07 \pm 1,47 \%$ de la LRC lo que difiere de Wyneken, (2001) ya que postula que esta estructura es más corta, sus cortes histológicos y los de los bronquios corresponde a lo planteado por Oros, (2004). El pulmón, que representa el $0,61 \pm 0,11 \%$ del peso del animal (Tablas 3 y 4), está conformado por faveolos, dicha observación indica unas estructuras más simples que los alveolos (Oros, 2004), lo cual manifiesta un área inferior de intercambio gaseoso, esto puede corresponder a un menor consumo de oxigeno comparado con los mamíferos, debido a un metabolismo más bajo (Mader, 1996). Macroscópicamente el pulmón en sus porciones craneales y caudal tienen zonas 
menos densas que pueden ser usadas por el animal para mantener la flotabilidad sobre el agua (Kardong, 1999).

\section{Sistema urogenital}

El sistema urogenital (Figuras 20 y 21) se inicia con los riñones (Rñ) y finaliza en la cloaca, donde se insertan las bolsas cloacales.

Riñón. Los riñones (Rñ) (Figuras 20 y 21) se encuentran en la parte dorsal dentro de la cavidad celómica en contacto en su borde craneal con los pulmones, en la zona media con la aorta descendente, y su porción caudal con el caparazón, ventral a los riñones se encuentran los intestinos. Se caracterizan por tener forma angular siendo los ángulos craneal y caudal los más agudos, y el ángulo obtuso medial, con presencia de un íleo donde ingresa la arteria renal y salen la vena renal y el uréter (Ur), internamente se observa un cáliz mayor.

Histología del riñón. Los riñones (Figura 22) muestran dos porciones una cortical externa $(\mathrm{Cz})$ y una medular $(\mathrm{Md})$ en las cuales se encuentran los aparatos yuxtaglomerulares, conformados por glomérulos (Gl) de un tamaño reducido y en pocas cantidades, y una capsula de bowman $(\mathrm{Cb})$ también reducida, que posee un epitelio plano simple. Se observa una alta presencia de túbulos contorneados estrechos ( $\mathrm{Tb}$ ), con tejido cubico simple, que difieren de los colectores de mayor calibre y de las asas de Henle $(\mathrm{AH})$.

Uréteres. Los uréteres de forma cilíndrica, se ubican mediales a los riñones de donde se originan, para descender de manera caudoventral hasta insertarse en el borde dorsal de la vejiga urinaria.

Histología del uréter. Los uréteres (Figura 23) presentan un epitelio cubico simple (Ecs) acompañado de tejido conectivo denso irregular, con agregados linfoides (Al) y con una capa muscular (Msc) poco definida. 

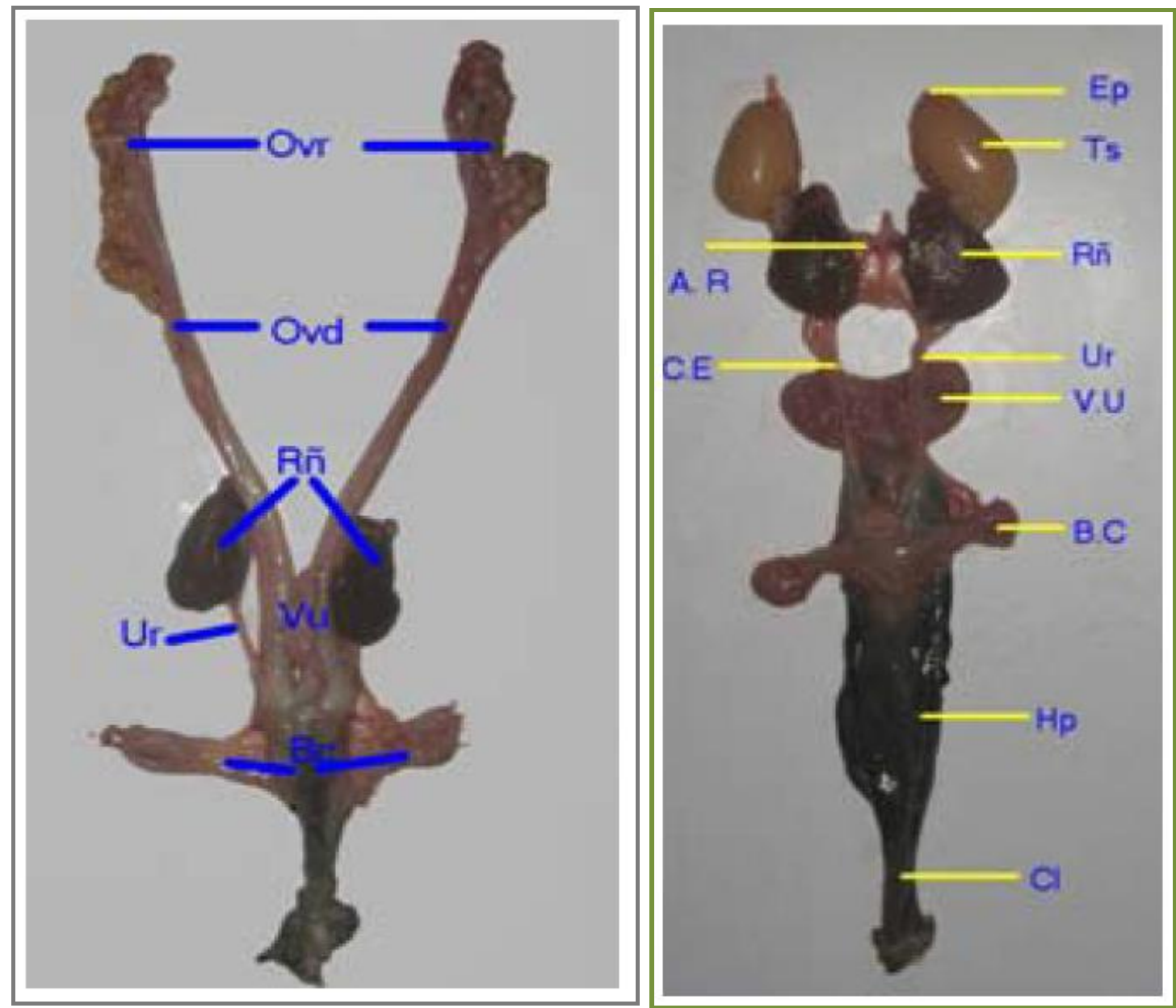

Figura 20. Sistema urogenital hembra. Ovr: Ovarios; Ovd: Oviductos; Rñ: Riñones; Ur: Uréter; Vu: Vejiga urinaria; Bc. Bolsas cloacales

Figura 21. Sistema urogenital hembra. Ovr: Ovarios; Ovd: Oviductos; Rñ: Riñones; Ur: Uréter; Vu: Vejiga urinaria; Bc. Bolsas cloacales
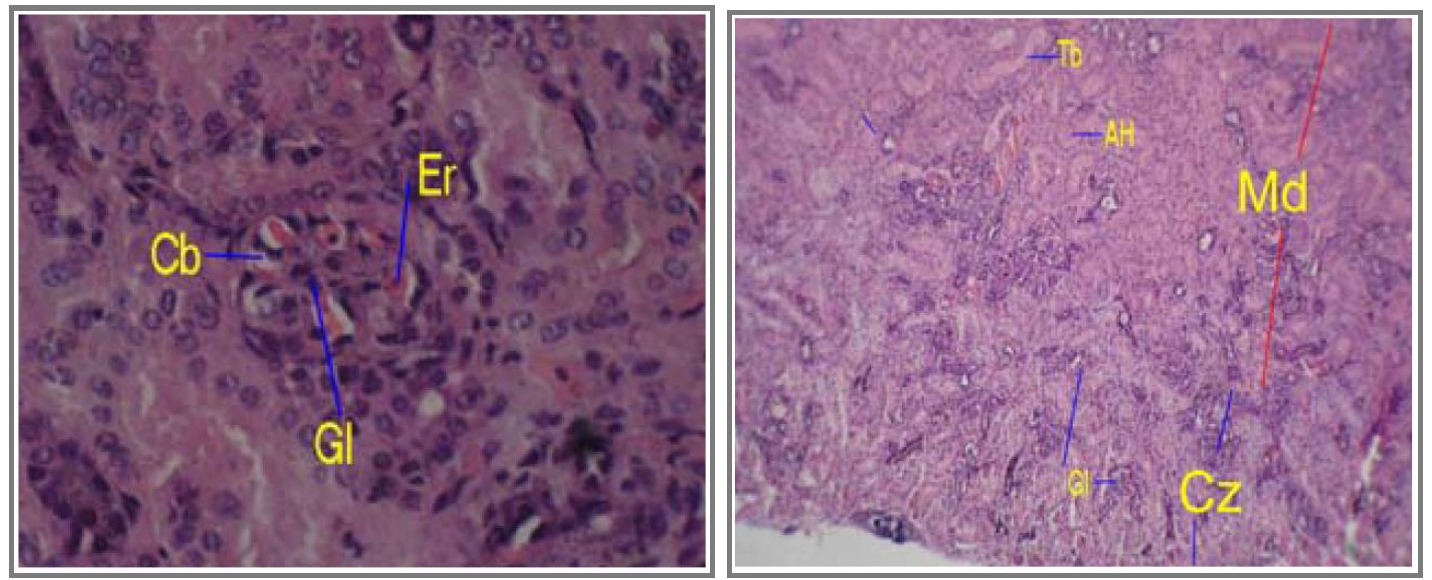

Figura 22. Corte histológico de riñón; Izquierda: aparato yuxtaglomerular 40X; Derecha: Parénquima renal $4 \mathrm{X}$ 
Vejiga urinaria. La ubicación de la vejiga urinaria $(\mathrm{Vu})$ (Figuras 20 y 21) cordiforme, es ventral, su porción anterior está en contacto dorsalmente con los intestinos y ventralmente con los músculos abdominales, teniendo su inserción en la cloaca sobre el pubis. Se caracteriza por tener una pared elástica la cual se encontró dilatada y contenida de líquido.

Histología de la vejiga urinaria. La vejiga (Figura 24) está conformada por epitelio de transición (Et), con agregados linfoides (Al), este tejido se organiza en pliegues vesicales $(\mathrm{Pg})$ debido al estado de la vejiga, dentro del tejido conectivo denso irregular se exhiben fibras de musculatura lisa (MI).

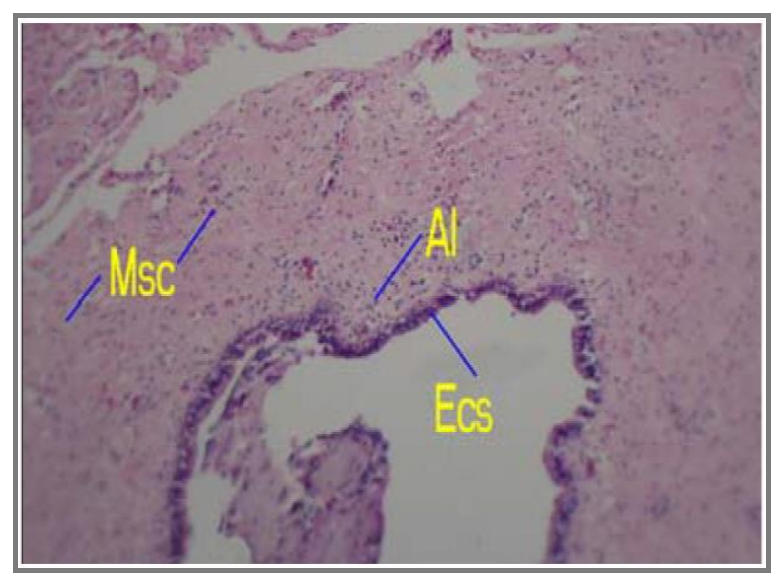

Figura 23. Corte histológico de uréter $4 \mathrm{X}$

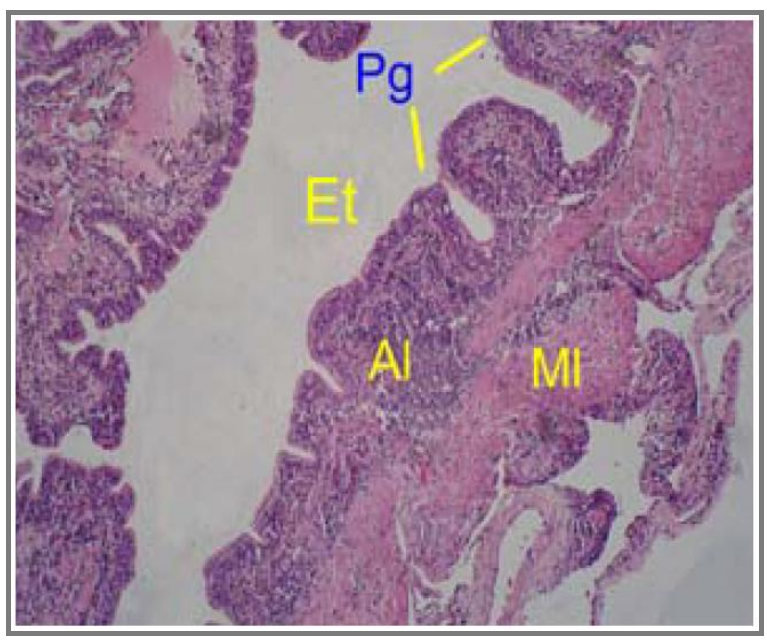

Figura 24. Corte histológico de vejiga urinaria $4 \mathrm{X}$

Ovarios. (Ovr) (Figura 25) Se encontraron en diferentes estados, algunos con folículos y ovocitos, simulando racimos de uvas, se ubican en los planos laterales de la cavidad celómica, su parte craneal está en contacto con los pulmones, donde el izquierdo limita con el borde caudal del lóbulo lateral izquierdo del hígado, su porción medial con los intestinos, la lateral con lo oviductos y con las paredes del celoma.

Histología de ovarios. En los ovarios (Figura 26) se presentan dos zonas una cortical y una medular difusa, en los ovocitos se encuentra una teca interna (TI) y 
una externa (TE) acompañados de la región germinal con células germinales, organizadas sobre un tejido conectivo denso irregular, tejido aerolar laxo adiposo (TA).

Oviducto. (Ovd) (Figuras 20 y 27) se encuentra en la posición lateral del tercer tercio del celoma, localizando su parte medial con los ovarios, la craneal con los intestinos en su porción media, dirigiéndose de manera caudo-medial hasta insertarse en la base de la cloaca.

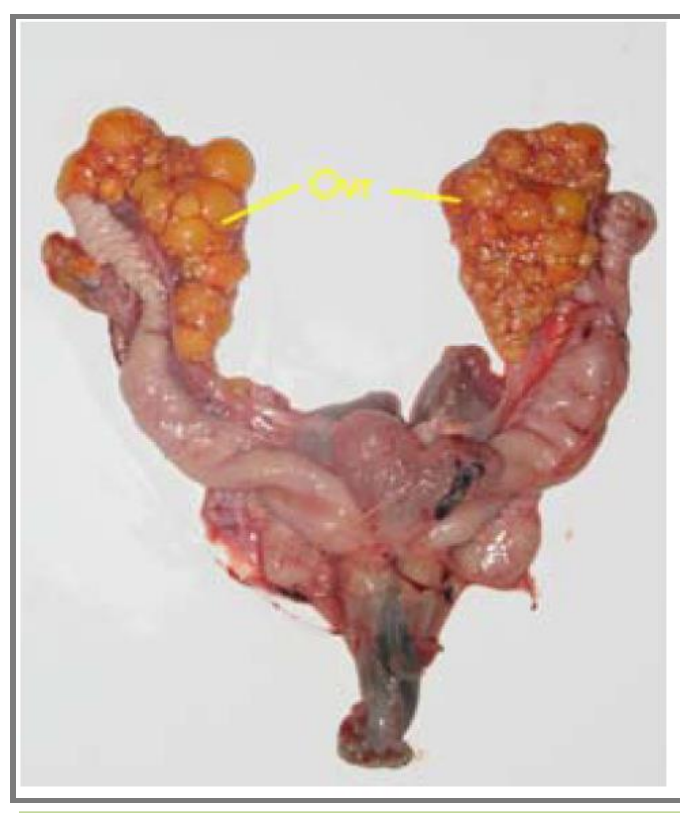

Figura 25. Ovarios: Ovr

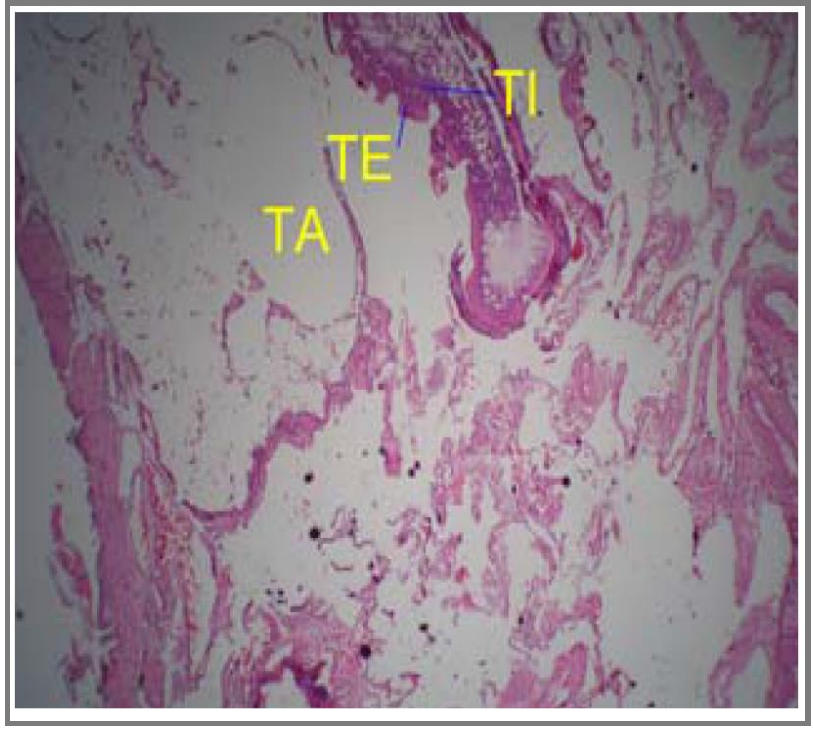

Figura 26. Corte histológico de ovario

Histología de oviducto. El epitelio del oviducto (Figura 28) es cilíndrico pseudoestratificado (Ep) con la exhibición de células caliciformes, siendo característica una zona luminal altamente irrigada ( $\mathrm{Zi}$ ), bajo el epitelio hay un tejido conjuntivo denso irregular y una capa muscular lisa gruesa (Msc).

Testículo. Los testículos, ovados, están ubicados en el tercer tercio de la cavidad celómica, el testículo derecho se encuentra dorsal al intestino anterior y ventral al riñón correspondiente, cranealmente limita con la primera asa del intestino anterior, el izquierdo se encuentra caudal al lóbulo izquierdo visceral del hígado, 
ventralmente queda en contacto con la membrana celomática, ambos testículos medialmente limitan con los riñones.

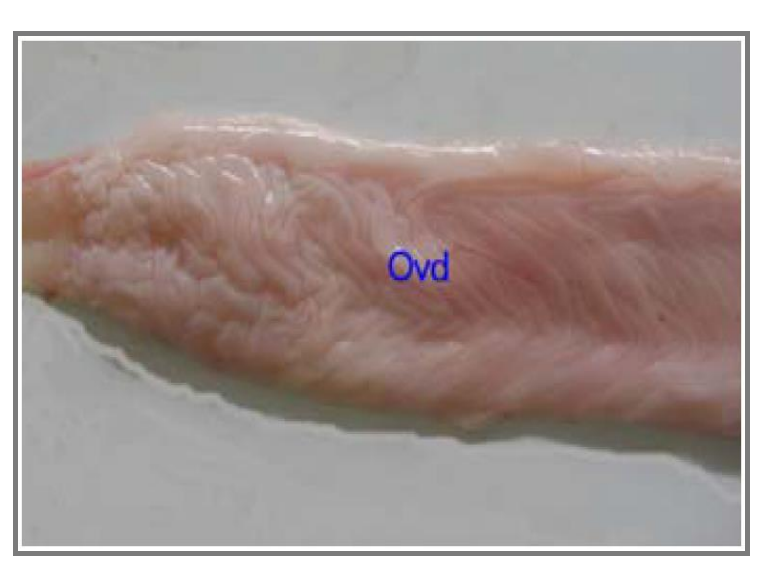

Figura 27. Oviducto: Ovd. Se aprecian los pliegues del oviducto

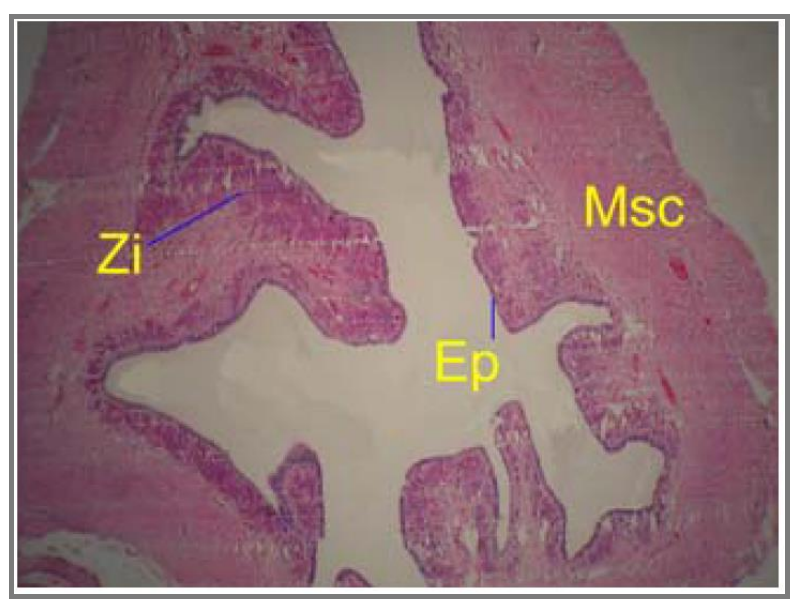

Figura 28. Corte histológico oviducto $4 \mathrm{X}$

Histología de testículo. Los testículos (Figura 29) están conformados por los túbulos seminíferos (Ts), en su lamina basal se encuentran las espermatogonias (Eg) que se van acercando a la luz hasta encontrar los espermatocitos (Es), ubicado en la lamina germinal y adyacente a éstas las células de Sertoli (Cs), estos túbulos están circundados por poco tejido conectivo y en su intersticio se ubican las células de Leydig $(\mathrm{CL})$, el testículo está cubierto por una túnica albugínea.
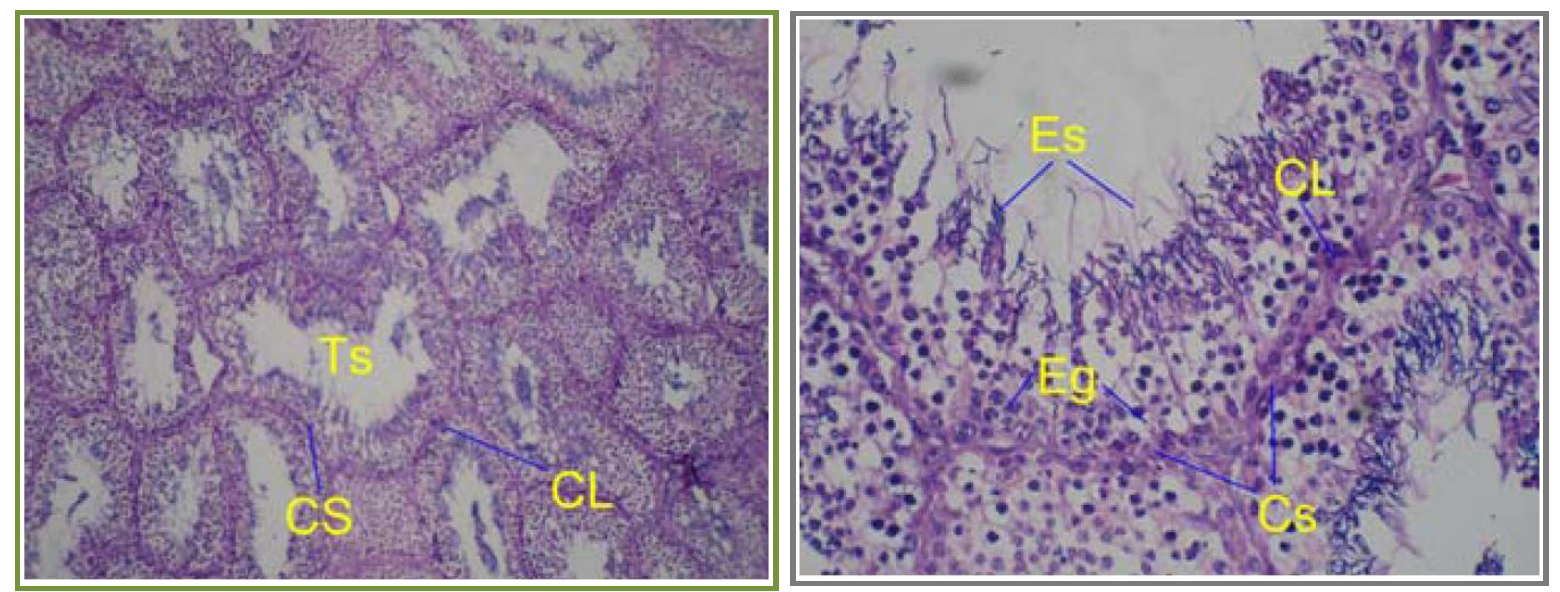

Figura 29. Cortes histológicos de testículo; Izquierda: Parénquima testicular 4X; Derecha: Células germinales y fases germinativas. 
Epidídimo. Los epidídimos se originan en el polo craneal de los testículos, dirigiéndose en forma de espiral por su porción medial hasta separarse de estos en el borde caudal, una vez liberados pasan a los conductos espermáticos.

Histología de epidídimo. El epidídimo (Figura 30) está compuesto por un epitelio cilíndrico ciliado pseudoestratificado (Ep), al cual llega la red de testis (Rt), que está conformada por un epitelio cubico simple, estas estructuras están circundadas por fibras musculares (Msc) y tejido denso irregular, el epidídimo está cubierto por una túnica albugínea.

Conducto deferente. Los conductos deferentes de forma cilíndrica, se originan en los epidídimos, y se insertan en la base del hemipene, en contacto con la vejiga.

Histología de conducto deferente. El conducto espermático o deferente (Figura 31) está conformado por un tubo central y otros anexos (Tacc), con epitelio cubico simple (Ep), recubiertos por tejido muscular liso (Msc) y conjuntivo, recubiertos por una túnica albugínea (Ta).

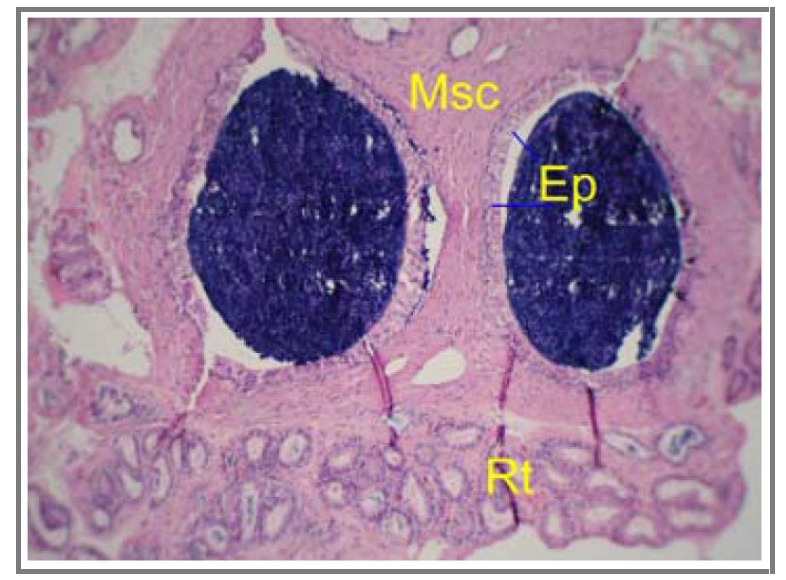

Figura 30. Corte histológico de epidídimo; en la zona superior se encuentra el epidídimo y en la inferior la red de testis.

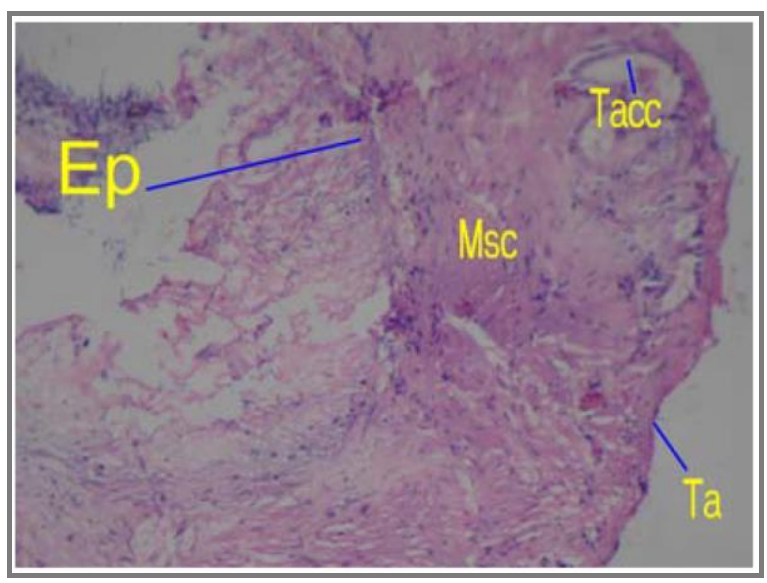

Figura 31. Corte histológico de conducto deferente $4 x$

Hemipene. El hemipene (Figura 32) de forma cuneiforme, se encuentra alojado en la zona ventral de la cloaca, caracterizado por tener cinco porciones, dos 
craneales alargadas (1), dos medidas (2) que se dilatan respecto a las anteriores y una caudal triangular (3), se aprecia orificio en esta última porción.

Histología de hemipene. El hemipene (Figura 33) se encuentra recubierto por una túnica albugínea (Ta), donde se albergan el musculo liso (ML) y tejido conjuntivo denso irregular, presentando tabiques, en los cuales se encuentran zonas vascularizadas (Zv) acompañadas de fibras colágenas y elásticas. Los cuerpos cavernosos poseen epitelio plano simple no queratinizado.

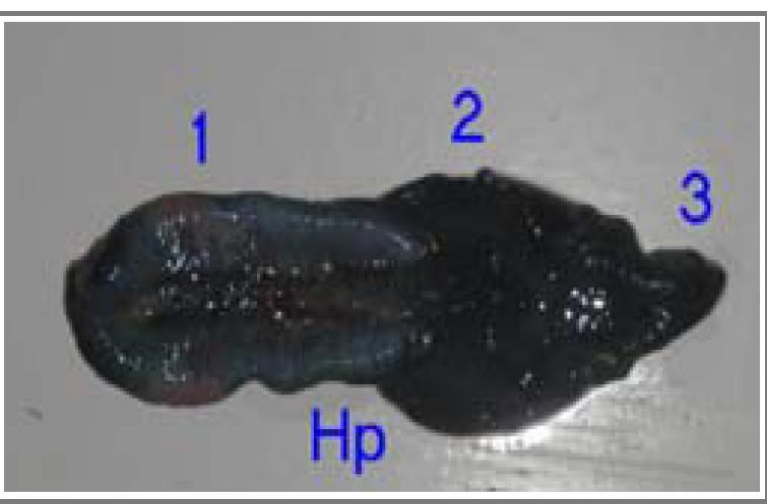

Figura 32. Hemipene: Porción anterior (1); Porción media (2); Porción posterior (3)

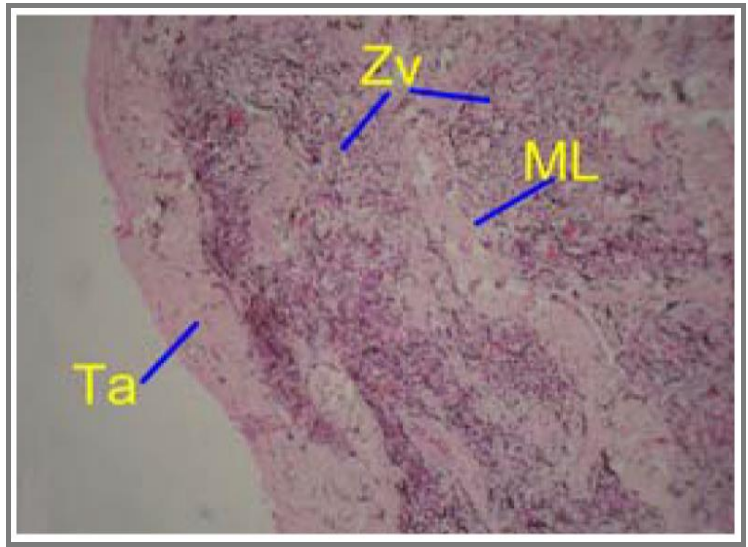

Figura 33. Corte histológico de hemipene $4 X$

Bolsas cloacales. Ubicadas lateralmente a la cloaca (Figura 34), en contacto con los músculos abdominales, caracterizados por ser dos sacos que se insertan en la cloaca.

Histología de bolsa cloacal. Las bursas cloacales (Figura 35) tiene un epitelio cilíndrico simple (EpT) sobre la lamina propia (Lp) y una túnica muscular de la mucosa (Ms $M$ ), en la que se encuentra una gran cantidad de tejido linfoide ( $A L)$, además se observa musculatura lisa $(\mathrm{ML})$ y se recubre por una lámina serosa $(\mathrm{S})$.

Cloaca. La cloaca se encuentra alojada sobre el pubis y dentro de la cintura pélvica, se prolonga dentro de la cola, se caracteriza por ser cilíndrica, y en su porción anterior aloja el urodeo proveniente de la vejiga urinaria, el coprodeo proveniente del intestino posterior, y las bolsas cloacales. 


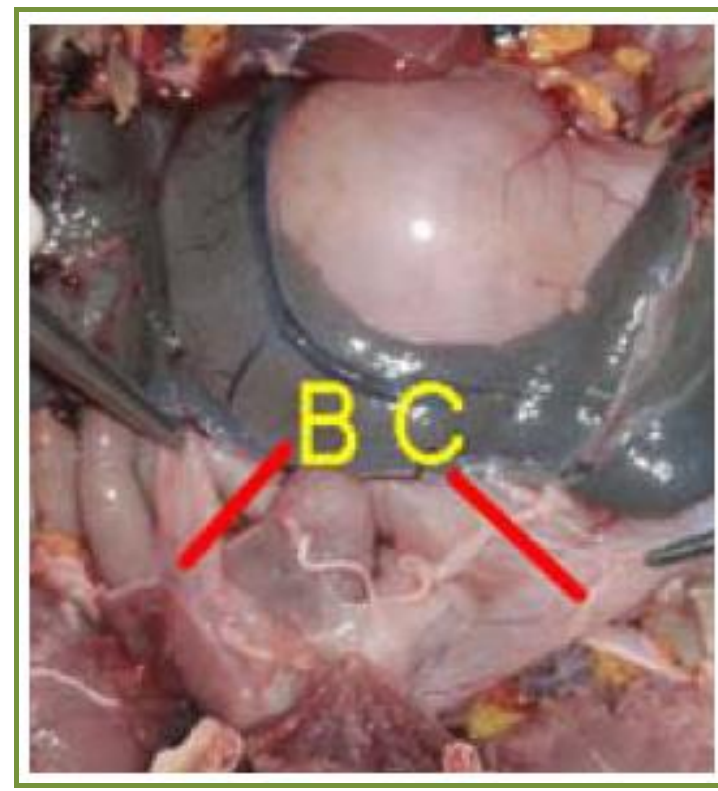

Figura 34. Bolsas cloacales

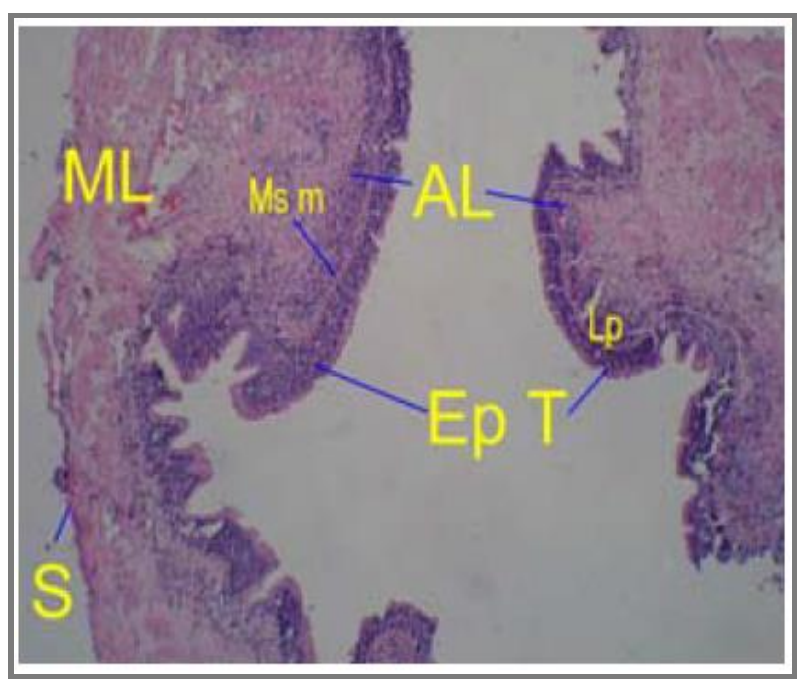

Figura 35. Corte histológico bolsa cloacal $4 \mathrm{X}$

Histología de cloaca. La cloaca (Figura 36) posee una mucosa con epitelio cilíndrico pseudoestratificado (Ecp) con células caliciformes (Cc), y en las ultimas porciones pasa a ser plano estratificado, la submucosa (Smc) contiene bastante tejido linfoide y adyacente a ésta se encuentra una gruesa capa muscular (Msc), por último se recubre por una túnica serosa externa.

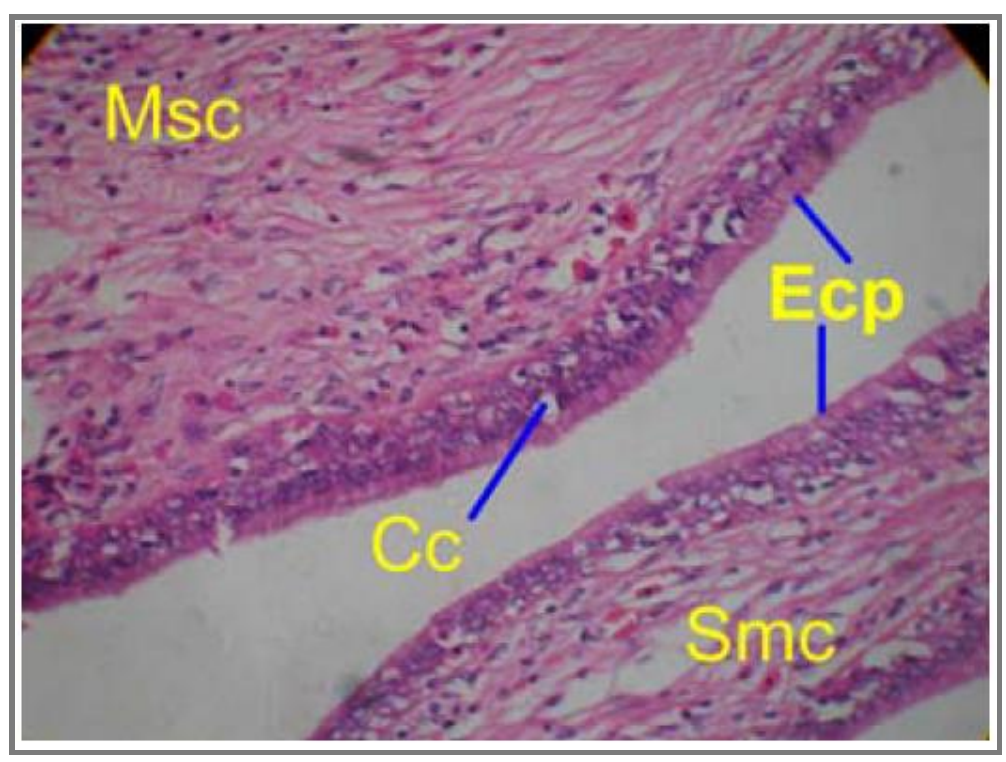

Figura 36. Corte histológico bolsa cloacal $4 \mathrm{X}$ 
Tabla 5. Morfometría sistema urogenital

\begin{tabular}{cccc}
\hline Órgano & Largo (cm) & Ancho (cm) & Peso (gr) \\
\hline Riñón derecho & $3,24 \pm 0,68$ & $1,97 \pm 0,42$ & $3,99 \pm 2,44$ \\
Riñón izquierdo & $3,24 \pm 0,66$ & $1,97 \pm 0,48$ & $3,87 \pm 2,28$ \\
Uréter derecho & $3,18 \pm 0,87$ & $0,27 \pm 0,09$ & $0,17 \pm 0,05$ \\
Uréter izquierdo & $3,26 \pm 0,73$ & $0,24 \pm 0,08$ & $0,21 \pm 0,12$ \\
Vejiga urinaria & $3,92 \pm 0,75$ & $5,06 \pm 0,94$ & $3,03 \pm 1,75$ \\
Ovario derecho & $11,95 \pm 3,10$ & $3,52 \pm 1,68$ & $39,07 \pm 32,31$ \\
Ovario izquierdo & $11,33 \pm 3,61$ & $4,38 \pm 2,06$ & $42,11 \pm 41,50$ \\
Oviducto derecho & $44,38 \pm 13,19$ & $1,42 \pm 0,25$ & $15,73 \pm 8,99$ \\
Oviducto izquierdo & $40,89 \pm 11,33$ & $1,28 \pm 0,58$ & $15,80 \pm 9,52$ \\
Testículo derecho & $2,02 \pm 0,53$ & $1,13 \pm 0,36$ & $1,29 \pm 0,6$ \\
Testículo izquierdo & $2,06 \pm 0,48$ & $1,26 \pm 0,25$ & $1,43 \pm 0,54$ \\
Epidídimo derecho & $4,90 \pm 1,51$ & $0,49 \pm 0,12$ & $0,25 \pm 0,11$ \\
Epidídimo izquierdo & $5,50 \pm 1,73$ & $0,48 \pm 0,18$ & $0,33 \pm 0,18$ \\
Conducto deferente der. & $2,36 \pm 0,34$ & $0,19 \pm 0,05$ & $0,10 \pm 0,01$ \\
Conducto deferente izq. & $2,35 \pm 0,55$ & $0,18 \pm 0,05$ & $0,09 \pm 0,01$ \\
Hemipene & $7,76 \pm 0,42$ & $2,15 \pm 0,05$ & $4,81 \pm 0,99$ \\
Bolsa cloacal derecha & $1,43 \pm 0,41$ & $5,32 \pm 0,95$ & $1,64 \pm 1,27$ \\
Bolsa cloacal izquierda & $1,36 \pm 0,33$ & $5,24 \pm 1,2$ & $1,37 \pm 0,84$ \\
Cloaca & $8,97 \pm 2,08$ & $1,65 \pm 0,91$ & $8,39 \pm 6,63$ \\
\hline
\end{tabular}

Los riñones topográficamente se encontraron de acuerdo a lo reportado por Wyneken, (2001); Chacón (2001) y Faria (2003) en tortugas: marinas, tortuga terecay y morroco negro respectivamente. Los tejidos de las asas de Henle fueron similares a los observados por Faria, (2003) pero diferentes a lo reportado por Chacón, (2001) y Oros, (2004) lo que ratifica que los reptiles por ser amniotas tienen riñones de tipo metanéfrico (Kardong, 1996). En adición se encontró que el tamaño de los glomérulos es pequeño y se presentan en poca cantidad (Chacón, 2001) (Tablas 5 y 6 ).

Los uréteres por ser conductos presentaron un epitelio cubico simple similar a lo reportado por Chacón, (2001) y en discrepancia con Faria, (2003) que propone epitelio estratificado simple y para el presente estudio no se halló moco neutro debido a que no se utilizaron tinciones diferenciales.

En los ovarios se logró diferenciar las tecas y las células germinales (Chacón, 2001), a diferencia de lo reportado por Romero et al., (1999) que caracterizan el estroma como septos formados por tejido conectivo, láminas elásticas y fibras 
musculares. El oviducto se exhibió macroscópicamente con estriaciones, lo que no se había reportado en la literatura. A diferencia de Chacón, (2001) no se encontró un útero. Por último, no se encontraron glándulas de esperma en los machos.

Tabla 6. Relación porcentual alométrica sistema urogenital

\begin{tabular}{cccccc}
\hline Órgano & $\begin{array}{c}\text { L/LRC } \\
(\%)\end{array}$ & $\begin{array}{c}\text { L/Plastrón } \\
(\%)\end{array}$ & $\begin{array}{c}\text { L/SMV } \\
(\%)\end{array}$ & $\begin{array}{c}\text { AnO/An } \\
(\%)\end{array}$ & $\begin{array}{c}\text { PO/Pan } \\
(\%)\end{array}$ \\
\hline Riñón derecho & $14,18 \pm 1,57$ & $15,61 \pm 1,75$ & $16,31 \pm 1,84$ & $11,65 \pm 1,44$ & $0,24 \pm 0,06$ \\
Riñón izquierdo & $14,36 \pm 2,71$ & $15,81 \pm 3,09$ & $16,53 \pm 3,33$ & $11,58 \pm 1,29$ & $0,23 \pm 0,03$ \\
Uréter derecho & $14,63 \pm 5,61$ & $16,20 \pm 6,45$ & $16,99 \pm 6,91$ & $1,59 \pm 0,44$ & $0,01 \pm 0,01$ \\
Uréter izquierdo & $14,79 \pm 4,64$ & $16,34 \pm 5,26$ & $17,14 \pm 5,74$ & $1,40 \pm 0,39$ & $0,01 \pm 0,01$ \\
Vejiga urinaria & $17,51 \pm 3,71$ & $19,28 \pm 4,13$ & $20,17 \pm 4,49$ & $30,26 \pm 5,01$ & $0,19 \pm 0,04$ \\
Ovario derecho & $45,01 \pm 10,57$ & $48,59 \pm 11,56$ & $50,25 \pm 12,17$ & $17,49 \pm 7,87$ & $1,47 \pm 1,08$ \\
Ovario izquierdo & $42,43 \pm 11,7$ & $45,77 \pm 12,59$ & $47,36 \pm 13,29$ & $21,89 \pm 9,56$ & $1,57 \pm 1,42$ \\
Oviducto derecho & $167,11 \pm 46,48$ & $180,14 \pm 49,79$ & $186,09 \pm 51,54$ & $7,13 \pm 1,02$ & $0,62 \pm 0,23$ \\
Oviducto izquierdo & $154,52 \pm 43$ & $166,52 \pm 46,03$ & $171,86 \pm 46,92$ & $6,47 \pm 2,87$ & $0,62 \pm 0,33$ \\
Testículo derecho & $10,62 \pm 2,81$ & $11,95 \pm 3,25$ & $12,61 \pm 3,39$ & $8,13 \pm 2,82$ & $0,15 \pm 0,07$ \\
Testículo izquierdo & $10,82 \pm 2,76$ & $12,71 \pm 3,16$ & $12,84 \pm 3,27$ & $9,02 \pm 2,06$ & $0,17 \pm 0,07$ \\
Epidídimo derecho & $25,56 \pm 7,15$ & $28,78 \pm 8,33$ & $30,36 \pm 8,68$ & $3,53 \pm 0,95$ & $0,03 \pm 0,01$ \\
Epidídimo izquierdo & $28,85 \pm 9,06$ & $32,49 \pm 10,47$ & $34,23 \pm 10,77$ & $3,51 \pm 1,54$ & $0,04 \pm 0,02$ \\
Conducto defe. der. & $12,33 \pm 1,65$ & $13,82 \pm 1,64$ & $14,61 \pm 1,81$ & $1,36 \pm 0,35$ & $0,01 \pm 0,00$ \\
Conducto defe. izq. & $12,26 \pm 2,65$ & $13,79 \pm 3,2$ & $14,54 \pm 3,19$ & $1,31 \pm 0,41$ & $0,01 \pm 0,00$ \\
Hemipene & $40,64 \pm 2,01$ & $45,63 \pm 2,33$ & $48,19 \pm 2,5$ & $15,37 \pm 3,98$ & $0,57 \pm 0,13$ \\
Bolsa cloacal der. & $6,21 \pm 0,97$ & $6,84 \pm 1,06$ & $7,14 \pm 1,07$ & $31,81 \pm 4,94$ & $0,09 \pm 0,03$ \\
Bolsa cloacal izq. & $5,95 \pm 0,74$ & $6,55 \pm 0,83$ & $6,84 \pm 0,89$ & $31,43 \pm 8,28$ & $0,08 \pm 0,02$ \\
Cloaca & $39,84 \pm 9,34$ & $43,88 \pm 10,46$ & $45,98 \pm 11,60$ & $9,19 \pm 3,75$ & $0,44 \pm 0,18$ \\
\hline L/LRC: Largo del órgano / Longitud Recta de Caparazón * $100 ;$ L/Plastrón: Largo órgano / Longitud de \\
Plastrón; L/SMV: Largo órgano / Sutura Media Ventral; AnO/An: Ancho órgano/Ancho animal * 100; PO/Pan: \\
Peso órgano / Peso animal * 100
\end{tabular}

En los testículos se encontró una túnica albugínea similar a la de serpientes (AlDokhi et al., 2004), adicionalmente se hallaron las células de Sertoli (Gribbins et al., 2005) al igual que las fases proliferativas descritas por éste, y que estas estructuras se encuentran acompañadas de las células de Leydig (Al-Dokhi et al., 2004).

En el epidídimo se observó la llegada de la red de testis, y el seguimiento del conducto deferente con un epitelio cubico simple y cinco porciones del hemipene, que no han sido reportadas en otros estudios con tortugas (Oros, 2004), pero compartiendo los conceptos de este autor se encontró la ranura uretral llamada saco espermático. Por último, las bolsas cloacales, tienen un epitelio cilíndrico 
simple que puede absorber agua la cual podría extraer el oxígeno disuelto para cubrir requerimientos de éste en condiciones de apnea.

\section{CONCLUSIONES}

Al describir las características de la anatomía e histología para los sistemas y órganos estudiados en tortuga sabanera Podocnemis vogli se puede concluir que los hallazgos son, en su mayoría, consecuentes con los resultados de estudios anteriores en reptiles y otros grupos de vertebrados. Sin embargo, fueron encontradas algunas particulares referentes a la forma, tamaño o presenciaausencia de algunos órganos y accesorios.

Se hallaron modificaciones histológicas con relación a los reportes de la literatura para reptiles que marcan diferencias respecto a los epitelios y las túnicas estructurales del tubo digestivo, acercando al tipo de alimentación y el comportamiento del bolo alimenticio en este tracto. De igual manera sucede en el sistema urinario, ya que las modificaciones encontradas acercan a la forma de excreción metanefrica, con presencia de una vejiga urinaria, realizada por este tipo de animales.

A pesar de que los resultados obtenidos para las morfometrías de los órganos, podrían no ser estadísticamente representativos, por el tamaño de la muestra, debe resaltarse que proporcionan información valiosa referente al tamaño estándar de dichos órganos y por ende se convierten en una herramienta valiosa de diagnostico de anormalidades morfológicas y fisiológicas presentadas en algún individuo de la especie.

\section{RECOMENDACIONES}

Se sugiere aplicar metodologías más completas de la ubicación de los órganos y sus morfologías in situ, por ejemplo, utilizando ayudas radiológicas o de ultrasonido, lo que demostrara la posición y forma de los órganos estando en animal vivo. 
Respecto a las morfologías, se podrían aplicar pruebas de capacidad volumétrica de los órganos, diferenciación morfométrica entre las posiciones de estos y relacionarlos con las medidas externas de los animales, lo que trae inmerso la ampliación de la muestra.

En la toma de las muestras histológicas, tomar estructuras de mayor tamaño a 1 $\mathrm{cm}$ de lado debido a que por la consistencia de los tejidos se lesionan y hacen difícil la lectura de placas. Para la diferenciación y/o reconocimiento de la presencia de algunas estructuras es necesario el uso coloraciones diferenciales que permitan evaluar con exactitud la composición histológica de un órgano.

\section{REFERENCIAS BIBLIOGRÁFICAS}

1. Al-Dokhi O. A., Al-Onazee Y. Z., Mubarak M. Light and Electron Microscopy of the Testicular Tissue of the Snake Eryx jayakari (Squamata, Reptilia) with a Reference to the Dividing Germ Cells. Journal of Biological Sciences 4 (3): 345-351. 2004.

2. Alibardi L., Thompson M. B. Scale morphogenesis and ultrastructure of dermis during embryonic development in the alligator (Allgator mississippiensis, Crocodilia, Reptilia). Acta Zoologica (Stockholm), 81: 325-338. 2000.

3. Alibardi L. Immunicytochemistry and keratinization in the epidermis of crocodilians. Zoologicl Studies, 42 (2): 346-356. 2003.

4. Avendaño I. Aproximación al conocimiento sobre la reproducción de los quelonios. Universidad Nacional de Colombia. Voluntarios Urras. Boletín GEAS. $2002 . \quad$ Disponible En: www.portalveterinaria.com/section. php?op=viewartiele\&artid=143\#top

5. Banks W. Histología Veterinaria Aplicada, segunda edición. Editorial manual moderno. 1996.

6. Ceballos C. P. Tortugas (Testudinata) marinas y continentales de Colombia. Biota Colombiana. p 187-194. 2000.

7. Chacón E. Aproximación a la descripción macroscópica y microscópica de los sistemas digestivo y urogenital de la Terecay (Podocnemis unifilis). Tesis como trabajo de grado para optar al título de Médico Veterinario y Zootecnista. Universidad de los Llanos. Facultad de ciencias agropecuarias y recursos naturales. Escuela de medicina veterinaria y zootecnia. Villavicencio. 2001.

8. Claude J. A geometric morphometric assessment of the effects of environment and cladogenesis on the evolution of the turtle shell. The linnean societu of London, Biological Journal of the Linnean Society, 79: 485-501. 2003.

9. Close B. Recomendaciones para la eutanasia de los animales de experimentación. University of Oxford. 1995 
10. Crews D., Fleming A., Willigham E. Role of steroidogenic Factor 1 and aromatase in temperature-dependent sex determination in the red eared slider turtle. Journal of Experimental Zoology, 290: 597-606. 2001.

11. Datta P. M. The first Jurassic turtle from India. Newsletter of the Paleontological Association. India, 43 (1): 99-109. 2000.

12. Dierenfeld E. S. Manual de nutrición y dietas para animales silvestres en cautiverio. Wild Life Conservation Society. Bronx NY. 1996.

13. Faria N. T. Topografía e morfología do sistema urinaria de jabuti "Geochelone carbonaria" (Spix, 1824). Tese (Doutorado). Universidad de Sao Paulo. 2003.

14. Fleming A., Wibbels T., Skipper, J. K. Developmental expression of steroidogenic Factor 1 in a turtle with temperature-dependent sex determination. General and Comparative Endocrinology, 116: 336-346. 1999.

15. Gribbins M. K, Happ C. S., Sever D. M. Ultrastructure of the reproductive system of the black swamp snake (Seminatrix pygaea). V. The temporal germ cell development strategy of the testis. Acta Zoologica (Stockholm) 86: 223230. 2005.

16. Haaparanta A. E., Tellervo, V., Hoffman R., Holmes, J. Do macrophage centres in freshwater fishes reflect the differences in water quality?. Aquatic Toxicology, 34: 253-272. 1996.

17. Haugarvoll E., Bjerkas I. Poppe T. T., Koppang E. O. Morphological and ultrastructural study of vaccine-induced granuloma in atlantic salmon (Salmo salar). Abstracts of the XXVth congress of the European association of veterinary anatomists (EAVA). Oslo. p 17. 2004.

18. Herrel A. O'reilly J.C. Richmond, A. M. Evolution of bite performance in turtles. J. Evol, B idol. 15 Blackwell Science Itd. 1083-1094. 2002.

19. Janeiro T. R. F. Variaca o anual do sistema reproductor de femeas de Bothrops jararacá (Serpentes, Viperidae). Iheringia, Sér. Zool., Porto Alegre, 94, (3): 325-328. 2004,

20. Kardong K. Vertebrados, anatomía comparada. Función, evolución. Mc Graw Hill - Interamericana. 1999.

21. Mader Dr. Reptile and medicine surgery. WB saunder company, Pennsylvania. 1996.

22. Martínez A S. Manual clínico de reptiles. Barcelona España. Grass iatros Ediciones. 1994.

23. Medem F. Medidas para las tortugas y crocodilia. Revista caldasia. Universidad Nacional de Colombia. 1975.

24. Moon P. F., Hernández S M. Reptiles: aquatic turtles (Chelonians). In: Zoological restraint and anesthesia, Hear d. (Ed) International Veterinary Infotmstion Service, Ithaca NY (www.ivis.org), B0118.0301. 2001.

25. Oros, J. Anatomía e Histología de reptiles. Universidad de las palmas de la Gran Canaria. 2004. Disponible En: http://www5.ulpgc.es/servidores/reptilia/

26. Pereira, J, G. Sousa K. R, Abreu-Silva A. L., Melo F. A. Costa, A. D. Histology of the spleen of the mucua Kinosternon scorpioides (Chelonia: Kinosternidae) Acta Microscopica, Volume 12, Supplement B. congress of the Brazilian Society for Microscopy and Microanalysis. 2003. 
27. Pough H, F. Vertebrate Life. Fifth edition. Arizona State University West. New Jersy. p 342-367. 1999.

28. Ramírez J. Tecnicas de recoleccion y control de calidad de huevos de tortugas y cocodrilos. Zoodivulgación, 1 (1): 32. 1999.

29. Rehorek S. J., Firth B. T., Hutchinson M. N. The structure of the nasal chemosensory system in squamate reptiles. The olfactory organ, with special reference to olfaction in geckos J. Biosci. Australia, 25: 173-179. 2000.

30. Rehorek S. J., Firth B. T., Hutchinson M. N. The structure of the nasal chemosensory system in squamate reptiles Lubricatory capacity of the vomeronasal organ. J. Biosci. Australia, 25 (2) 181-190. 2000.

31. Rieppel O. Turtles as diapsid reptiles. Zoologica Scripta, 29: 199-212. 2000.

32. Rodríguez R. F., Miglino M. A., Melo A. P. F. Vascularização arterial do trato gastrointestinal da trachemys scripta elegans, Wied, 1838. Brazilian Journal of Veterinary Research and Animal Science, 40: 63-68. 2003.

33. Romero G., Ramírez M. P., Calderón M. L. Estudio preliminar de la ultraestructura de la pared del ovario y de folículos previtelogénicos y vitelogénicos tempranos de Caimán Crocodilus fuscus (Reptilia, Crocodylidae). Rev. Acab. Colomb. Cienc., 23: 452-464. 1999

34. Rueda J. V., Rueda J. N. Las tortugas y crocodylia de Colombia: Manual para su identificación. Bogotá. Ed not Pub. 2003.

35. Sacristan A. Fisiología veterinaria. New York, United States of America. Editorial McGraw Hill. 1995.

36. Saito K., Shoti T., Uchida I., Ueda H. Structure of the olfatory and vomeronasal epithelia in loggehead turtle Caretta caretta. Department of biology. Hokkaio University. Fisheries Science, 66: 409-411. 2000.

37. Slack J. M. W. Developmental biology of the pancreas. Development, Great Britain. 121: 1569-1580. 1995.

38. Tedesco M., Fiorito L. E., Pereyra L. A. Estudio preliminar de la membrana timpánica en algunas especies de lagartos de la familia Teiidae (Reptilia, squamata). Universidad Nacional del Nordeste. Comunicaciones Científicas y Tecnológicas. Resumen: B-11. 2003.

39. Tedesco M. E., Hermida G. N., Fiorito L. E. Morfología pulmonar interna en tres especies de lagartos de la familia Teiidae (Reptilia-Squamata). Universidad Nacional del Nordeste. Comunicaciones Científicas y Tecnológicas. Resumen: B-034. 2004.

40. Valenzuela N., Adams D. C., Janzen F. J. Pattern does not equal process: Exactly when is sex environmentally determined?. The American Naturalist, 161 (4): 676-683. 2003.

41. Varela, N. Bases de nutrición en fauna silvestre fuente: boletín GEAS. Boletín del grupo de estudio de animales silvestres. Universidad Nacional de Colombia. 5 (1). 2003.

42. Vogelbein W. K., Fournie J. W., Overstreet R. M. Sequential development and morphology of exzperimentally induced hepatic melanomacrophage centre in Rivulus marmoratus, J. Fish boil., 31: 145-153. 1987.

43. Wyneken J. The anatomy of sea turtles. Southeast Fisheriast Science Center. Miami. p 1-172. 2001. 